\title{
Polycyclic aromatic hydrocarbons (PAHs) and their alkylated-, nitro- and oxy-derivatives in the atmosphere over the Mediterranean and Middle East seas
}

Marco Wietzoreck ${ }^{1}$, Marios Kyprianou ${ }^{2}$, Benjamin A. Musa Bandowe ${ }^{1}$, Siddika Celik ${ }^{3}$, John N. 5 Crowley $^{4}$, Frank Drewnick ${ }^{3}$, Philipp Eger ${ }^{4}$, Nils Friedrich ${ }^{4}$, Minas Iakovides ${ }^{2}$, Petr Kukučka ${ }^{5}$, Jan Kuta ${ }^{5}$, Barbora Nežiková ${ }^{5}$, Petra Pokorná ${ }^{6}$, Petra Přibylová ${ }^{5}$, Roman Prokeš 5,7 , Roland Rohloff ${ }^{4}$, Ivan Tadic ${ }^{4}$, Sebastian Tauer ${ }^{4}$, Jake Wilson ${ }^{1}$, Hartwig Harder ${ }^{4}$, Jos Lelieveld ${ }^{2,4}$, Ulrich Pöschl ${ }^{1}$, Euripides G. Stephanou ${ }^{2,8}$, Gerhard Lammel ${ }^{1,5}$

${ }^{1}$ Multiphase Chemistry Department, Max Planck Institute for Chemistry, Mainz, 55128, Germany

$10{ }^{2}$ Climate and Atmosphere Research Centre, Cyprus Institute, Nicosia, 2121, Cyprus

${ }^{3}$ Particle Chemistry Department, Max Planck Institute for Chemistry, Mainz, 55128, Germany

${ }^{4}$ Atmospheric Chemistry Department, Max Planck Institute for Chemistry, Mainz, 55128, Germany

${ }^{5}$ RECETOX, Faculty of Science, Masaryk University, Brno, 625 00, Czech Republic

${ }^{6}$ Department of Aerosol Chemistry and Physics, Institute of Chemical Process Fundamentals of the CAS, Prague, 16502 ,

15 Czech Republic

${ }^{7}$ The Czech Academy of Sciences, Global Change Research Institute, Brno, 603 00, Czech Republic

${ }^{8}$ Department of Chemistry, University of Crete, Heraklion, 70013, Greece

Correspondence to: Gerhard Lammel (g.lammel@mpic.de)

Abstract. Polycyclic aromatic hydrocarbons (PAHs), their alkylated (RPAHs), nitrated (NPAHs) and oxygenated (OPAHs)

20 derivatives are air pollutants. Many of these substances are long-lived, can undergo long-range atmospheric transport and adversely affect human health upon exposure. However, the occurrence and fate of these air pollutants has hardly been studied in the marine atmosphere. In this study, we report the atmospheric concentrations over the Mediterranean Sea, the Red Sea, the Arabian Sea, the Gulf of Oman and the Arabian Gulf, determined during the AQABA (Air Quality and Climate Change in the Arabian Basin) project, a comprehensive ship-borne campaign in summer 2017. The average concentrations of

$25 \sum_{27} \mathrm{PAHs}, \sum_{19} \mathrm{RPAHs}, \sum_{11} \mathrm{OPAHs}$ and $\sum_{17} \mathrm{NPAHs}$, in the gas and particulate phase, were $2.85 \pm 3.35 \mathrm{ng} \mathrm{m}^{-3}, 0.83 \pm 0.87 \mathrm{ng}$ $\mathrm{m}^{-3}, 0.24 \pm 0.25 \mathrm{ng} \mathrm{m}^{-3}$ and $4.34 \pm 7.37 \mathrm{pg} \mathrm{m}^{-3}$, respectively. The Arabian Sea region was the cleanest for all substance classes, with concentrations among the lowest ever reported. Over the Mediterranean Sea, we found the highest average burden of $\sum_{26} \mathrm{PAHs}$ and $\sum_{11} \mathrm{OPAHs}$, while the $\sum_{17} \mathrm{NPAHs}$ were most abundant over the Arabian Gulf (known also as Persian Gulf). 1,4-Naphthoquinone (1,4- $\left.\mathrm{O}_{2} \mathrm{NAP}\right)$ followed by 9-fluorenone and 9,10-anthraquinone were the most abundant studied

OPAHs in most samples. The NPAH composition pattern varied significantly across the regions, with 2-nitronaphthalene (2NNAP) being the most abundant NPAH. According to source apportionment investigations, the main sources of PAH derivatives in the region were ship exhaust emissions, residual oil combustion and continental pollution. All OPAHs and NPAHs except 2-NFLT, which were frequently detected during the campaign, showed elevated concentrations in fresh shipping emissions. In contrast, 2-nitrofluoranthene (2-NFLT) and 2-nitropyrene (2-NPYR) were highly abundant in aged 
shipping emissions due to secondary formation. Apart from 2-NFLT and 2-NPYR, also benz(a)anthracene-7,12-dione and 1,4- $\mathrm{O}_{2} \mathrm{NAP}$ had significant photochemical sources. Another finding was that the highest concentrations of PAHs, OPAHs and NPAHs were found in the sub-micrometre fraction of particulate matter $\left(\mathrm{PM}_{1}\right)$.

\section{Introduction}

Air pollution contributes to the global burden of respiratory and cardiovascular diseases (Shiraiwa et al., 2017; Lelieveld et al., 2019). The Red Sea and especially the Arabian Gulf region are prone to major risks by air particulate matter (PM) and gas phase pollutants due to the hot and arid climate leading to high dust concentrations and photochemical activity (Lelieveld et al., 2009). In combination with high anthropogenic emissions from highly populated cities, intense marine traffic due to major trade routes (Johansson et al., 2017) and a strong petrochemical industry, air pollution can be significant in these regions (Lelieveld et al., 2015).

45 One major class of air pollutants are polycyclic aromatic hydrocarbons (PAHs) and their alkylated (RPAHs), nitrated (NPAHs) and oxygenated (OPAHs) derivatives. Several of these substances are classified as carcinogenic or possibly carcinogenic (IARC, 1983, 1989, 2018; OEHHA, 2021). Moreover, many polycyclic aromatic compounds (PACs) show strong mutagenic (Durant et al., 1996; Clergé et al., 2019) and ecotoxic effects (el Alawi et al., 2002; Sverdrup et al., 2002a, b). Quinones, a major subgroup of OPAHs, have received more attention in recent years due to their potential to contribute

50 to oxidative stress on cell level (Bolton et al., 2000; Walgraeve et al., 2010; Xiong et al., 2017; Lyu et al., 2018). Although some PAH derivatives show even higher toxicity than their parent PAHs (Durant et al., 1996; Collins et al., 1998; Turcotte et al., 2011; IARC, 2018; Lee et al., 2017; Clergé et al., 2019), their atmospheric concentrations, their cycling and fate are not well studied. Alkylated 3-ring-PAHs are more persistent, bioaccumulative, and toxic than the parent 3-ring-PAHs, which have been identified within Europe (ECHA, 2021) as substances with persistent, bioaccumulative, and/or toxic properties

55 (PBT). According to Wassenaar and Verbruggen (2021) alkylated 3-ring-PAHs could also be considered as PBT.

PAHs, OPAHs, NPAHs and RPAHs are formed by incomplete combustion of fossil fuels, biomass and waste (Baek et al., 1991; Lee et al., 2003; Walgraeve et al., 2010; Bandowe and Meusel, 2017). Apart from these pyrogenic sources, PAHs, especially low-molecular-weight PAHs and RPAHs, and some PAH derivatives can originate from petrogenic sources and spills of petroleum hydrocarbons (Andersson and Achten, 2015; Zhao et al., 2015; Abbas et al., 2018). In addition to these so-called primary emissions, NPAHs and OPAHs can also be formed by secondary formation by reactions of PAHs with atmospheric oxidants (Finlayson-Pitts and Pitts, 1999; Keyte et al., 2013). For most PAH derivatives, the contribution from secondary formation is not known. It was shown that 2-nitrofluoranthene (2-NFLT) is formed in gas phase reactions and was not found in direct emissions, while the opposite was reported for 1-nitropyrene (1-NPYR) (Arey et al., 1986; Bamford and Baker, 2003). Therefore, the ratio 2-NFLT/1-NPYR can be used as an indicator for the relative contributions of secondary formation reactions in the gas phase compared to primary emitted compounds (Bamford and Baker, 2003). 
The concentration of PAHs in ambient air as well as other environmental compartments has been studied quite extensively in the last decades (Baek et al., 1991; Srogi, 2007; Ravindra et al., 2008), especially for the 16 USEPA-prioritized PAHs (Keith, 2015). However, our knowledge about the distribution of PAH derivatives is still limited (Andersson and Achten, 2015; Lammel, 2015; Bandowe and Meusel, 2017; Iakovides et al., 2021). There are several studies reporting atmospheric concentrations of OPAHs and NPAHs in the particulate and the gas phase at urban and semi-urban sites (Bamford and Baker, 2003; Garcia et al., 2014; Li et al., 2015; Tomaz et al., 2016; Alves et al., 2017; Kitanovski et al., 2020). Rural/continental background and remote continental sites were investigated in a small number of studies, indicating that several NPAHs and OPAHs are ubiquitous (Ciccioli et al., 1996; Tsapakis and Stephanou, 2007; Brorström-Lundén et al., 2010; Scipioni et al., 2012; Tang et al., 2014; Nežiková et al., 2021). Their detection in the Antarctic (Vincenti et al., 2001;

75 Minero et al., 2010) confirms the long-range transport potential (Keyte et al., 2013). This is supported by global modelling studies of NPAHs (Wilson et al., 2020; Kelly et al., 2021). However, fewer studies have determined the pollutant concentrations in the marine environment, in polluted sea regions or in marine background air. Tsapakis and Stephanou (2007) and Lammel et al. (2017) measured NPAHs and OPAHs at an eastern Mediterranean marine background location, while Zhang et al. (2018) sampled air on Tuoji Island in the Yellow Sea. To the best of our knowledge, there is no study measuring NPAHs and OPAHs over the open ocean. The knowledge about the sources of pollution and the atmospheric fate processes such as gas-particle partitioning, photochemical degradation and deposition in the marine environment is crucial for understanding the distribution and fate of these pollutants, although very little is known (Keyte et al., 2013). In addition, these processes in marine air are crucial for modelling the distribution of these substances and the concentrations are needed for the validation of modelling results (Wilson et al., 2020).

85 The objective of this study was to determine the concentrations in the gas and particulate phase of the PAHs, RPAHs, NPAHs and OPAHs in the Mediterranean Sea and around the Arabian Peninsula including the Red Sea, Arabian Sea and the Arabian Gulf region. We aimed to study the gas-particle partitioning and the mass size distributions of PACs in the atmosphere of a hot marine environment. Furthermore, we provide information about the sources of air pollution in these regions.

\section{Methods}

\subsection{The AQABA ship campaign}

The Air Quality and Climate in the Arabian Basin (AQABA) campaign took place in summer 2017 from the 25 June until the 01 September 2017, sailing on a research vessel (Kommandor Iona) from Toulon, France, to Kuwait City, Kuwait, and back, with a 2-day stop in Jeddah, Saudi Arabia (first leg) and a 5-day stop in Kuwait. The sampling was performed only during cruise and outside the 12 nautical miles zones of the countries in the Mediterranean Sea (MS), Suez Canal, Red Sea (RS), Arabian Sea (AS, in the northern Indian Ocean), Gulf of Oman (OG) and the Arabian Gulf (AG, also known as the Persian Gulf). For the evaluation, the Red Sea is split into northern Red Sea (NRS) and southern Red Sea (SRS). The Suez 
Canal is included into the northern Red Sea region; the Gulf of Aden is part of the Arabian Sea. The sampling regions and sampling cruises are shown in Fig. S1 in the Supplement.

\subsection{Sampling}

\subsubsection{Air sampling for analysis of PAHs, OPAHs and NPAHs}

The air pollutants were sampled separately in gas and particulate phases in polyurethane foams (PUFs, Molintan a.s., Břeclav, Czech Republic) and on quartz microfibre filters (QFFs, QMA type, Whatman, Sheffield, United Kingdom), respectively, by active air sampling on the observation deck (in the front part of the vessel, around $7.7 \mathrm{~m}$ a.s.1. and $55 \mathrm{~m}$ away from the stack). The aerosol was sampled as $\mathrm{PM}_{10}$ (all particles with an aerodynamic equivalent diameter of $<10 \mu \mathrm{m}$ ) by a Digitel sampler (DH77, Hegnau, Switzerland). Additionally, PM was collected size-segregated with 6 size fractions (5 stages + backup filter) within $\mathrm{PM}_{10}\left(\mathrm{PM}_{<0.49 \mu \mathrm{m}}\right.$ (backup filter), $\mathrm{PM}_{0.49-0.95 \mu \mathrm{m}}, \mathrm{PM}_{0.95-1.5 \mu \mathrm{m}}, \mathrm{PM}_{1.5-3 \mu \mathrm{m}}, \mathrm{PM}_{3-7 \mu \mathrm{m}}$ and $\left.\mathrm{PM}_{7-10 \mu \mathrm{m}}\right)$ using a high-volume sampler (Baghirra HV 100-P, Prague, Czech Republic) equipped with a cascade impactor inlet (TE235, Tisch Environmental, Inc., Cleves, USA). All filters were pre-baked at $300{ }^{\circ} \mathrm{C}$ for $12 \mathrm{~h}$ and the PUFs were pre-cleaned $(8 \mathrm{~h}$ Soxhlet extraction in acetone and $8 \mathrm{~h}$ in dichloromethane (DCM)) before wrapping them into two layers of aluminium foil, placing into zip-lock polyethylene bags and keeping them frozen at $-20{ }^{\circ} \mathrm{C}$ prior to deployment. After exposure, the samples were wrapped in aluminium foil and kept in polyethylene zip-lock bags at $-20{ }^{\circ} \mathrm{C}$ during storage. During the whole cruise, 62 air samples (gas and particulate phase) and 30 size-resolved PM samples were collected together with 6 field blanks. Detailed sampling information is provided in Supplement Fig. S1 and in Table S1.

\section{2.2.1 Air sampling for analysis of PAHs and RPAHs}

45 air (gas and particulate phase) samples for the determination of PAHs and alkylated PAHs were collected on the monkey deck of the research vessel (around $4 \mathrm{~m}$ higher and $5 \mathrm{~m}$ less far away from the stack compared to the samplers for PAHs, OPAHs and NPAHs) during the campaign, using a high-volume air sampler (GMWL-2000H; General Metal Works, Cleves, USA). In contrast to the Digitel high volume sampler, total suspended particles (TSP) instead of $\mathrm{PM}_{10}$ were collected. The sampling duration varied from 6 to $24 \mathrm{~h}$ and the total volume of each air sample ranged from 318 to $1428 \mathrm{~m}^{3}$ (Table $\mathrm{S} 1$ in the Supplement). Pre-combusted QFFs $\left(3 \mathrm{~h}\right.$ at $\left.420{ }^{\circ} \mathrm{C}\right)$ and pre-extracted PUF plugs $(8.0 \times 7.5 \mathrm{~cm}$, Ziemer, Langerwehe, Germany) were used for the collection of particulate and gaseous phases, respectively. TSP mass was gravimetrically determined. Filters were pre- and post-sampling weighed on a microbalance (KERN GmbH, Balingen, Germany; $1.0^{-5} \mathrm{~g}$ readability) at constant temperature $\left(21 \pm 2{ }^{\circ} \mathrm{C}\right)$ and relative humidity $(45 \pm 10 \%)$ conditions. 


\subsection{Sample preparation and analysis}

\subsubsection{PAHs, OPAHs and NPAHs}

PUFs and QFFs were extracted using automated Soxhlet extraction (40 minutes Soxhlet extraction followed by 20 minutes of solvent rinsing) with DCM in a B-811 extraction unit (Büchi, Flawil, Switzerland). Prior to extraction, the samples were spiked with deuterated nitro-PAHs (1-nitronaphthalene-d7, 2-nitrofluorene-d9, 9-nitroanthracene-d9, 3-nitrofluoranthene-d9, 1-nitropyrene-d9, 6-nitrochrysene-d11, 6-nitrobenzo[a]pyrene-d11) and deuterated PAHs (d8-naphthalene, d10phenanthrene, d12-perylene) as surrogate standards.

The extract was cleaned up using a silica column ( $5 \mathrm{~g}$ of silica, $0.063-0.200 \mathrm{~mm}$, activated at $150{ }^{\circ} \mathrm{C}$ for 12 hours, $10 \%$ deactivated with water) and $1 \mathrm{~g} \mathrm{Na}_{2} \mathrm{SO}_{4}$. The sample was loaded onto the column and the target substances were eluted by 5 $\mathrm{mL} n$-hexane, followed by $50 \mathrm{~mL}$ DCM. The volume of the eluate was then reduced by a stream of nitrogen in a TurboVap

135 II (Caliper LifeSciences, Mountain View, USA) concentrator unit and transferred into a GC vial, spiked with p-terphenyl and PCB 121 (syringe standards), and the final volume in the vial was adjusted to $200 \mu \mathrm{L}$.

Polycyclic aromatic compounds (PACs) in the sample extracts were analysed at the Trace Analytical Laboratory of the research centre RECETOX at the Masaryk University in Brno, Czech Republic, similar to the method described by Nežiková et al. (2021). The target compounds in this analysis were 26 PAHs, 1S-heterocycle, 1 RPAH, 17 NPAHs and 11 OPAHs. All

140 target PAHs, OPAHs and NPAHs including their acronyms are shown in Table 1. The physico-chemical properties of all targeted compounds are shown in Table S2.

The analysis of PAHs was performed by gas chromatography (GC, 7890A, Agilent, Santa Clara, USA) equipped with a 60 m x $0.25 \mathrm{~mm}$ x $0.25 \mu \mathrm{m}$ Rxi-5Sil MS column (Restek, Bellefonte, USA) coupled to a mass spectrometer (MS, 7000B triple quadrupole, Agilent, Santa Clara, USA). $1 \mu \mathrm{L}$ of sample was injected splitless at $280{ }^{\circ} \mathrm{C}$ with $\mathrm{He}$ as carrier gas at a constant

145 flow rate of $1.5 \mathrm{~mL} \mathrm{~min}^{-1}$. The GC program was as follows: $80{ }^{\circ} \mathrm{C}(1 \mathrm{~min}$ hold $)$, then heated at a rate of $15^{\circ} \mathrm{C} \mathrm{min}{ }^{-1}$ to 180 ${ }^{\circ} \mathrm{C}$, followed by $5{ }^{\circ} \mathrm{C} \min ^{-1}$ to $310{ }^{\circ} \mathrm{C}(20 \mathrm{~min}$ hold). The MS was operated in positive electron ionization (EI+) mode with selected ion monitoring (SIM). The SIM $\mathrm{m} / \mathrm{z}$ ratios and the retention times of the targeted PAHs are shown in Table S3a.

NPAHs and OPAHs were analysed by GC atmospheric pressure chemical ionization tandem mass spectrometry (GC-APCIMS/MS) on a Waters Xevo TQ-S MS (Waters, Mildford, USA) coupled to a GC (GC 7890, Agilent, Santa Clara, USA). The

150 MS was operated under dry source conditions in multiple reactions monitoring (MRM) mode. The GC was fitted with a 30 $\mathrm{m} \times 0.25 \mathrm{~mm} \times 0.25 \mu \mathrm{m}$ Rxi-5Sil MS column (Restek, Bellefonte, USA). The injection of $1 \mu \mathrm{L}$ of the sample was splitless at $270{ }^{\circ} \mathrm{C}$. He was used as carrier gas at a constant flow rate of $1.5 \mathrm{~mL} \mathrm{~min}^{-1}$. The oven temperature program was as follows: 90 ${ }^{\circ} \mathrm{C}$ ( 1 min hold), then heated at a rate of $40{ }^{\circ} \mathrm{C} \min ^{-1}$ to $180{ }^{\circ} \mathrm{C}$, followed by $5{ }^{\circ} \mathrm{C} \min ^{-1}$ to $320{ }^{\circ} \mathrm{C}$ (6 min hold). The MRM $\mathrm{m} / \mathrm{z}$ ratios and the retention times of the targeted OPAHs and NPAHs are given in Table S3b. 


\subsubsection{RPAHs}

For alkylated PAHs, particulate and gas-phase samples were extracted and cleaned-up separately following a procedure described in detail elsewhere (Iakovides et al., 2021). Each fraction was reduced to approximately $0.3 \mathrm{~mL}$ by rotary evaporation, transferred to $1.1 \mathrm{~mL} \mathrm{GC}$ vials and further evaporated almost to dryness under a gentle stream of nitrogen at -10 ${ }^{\circ} \mathrm{C}$ to minimize evaporation losses. Prior to GC/MS analysis, a known amount of internal standard mixture (4-20 ng of

160 anthracene- $\mathrm{d}_{10}$ in iso-octane) was added in each GC vial to assess the analyte recovery in the collected samples. The sample extracts were analysed at the Cyprus Institute (Cyprus). The target compounds in this analysis were phenanthrene (PHE) and 18 RPAHs, which are shown in Table 1.

The analysis was carried out on a GC (7890N GC, Agilent, Santa Clara, USA) equipped with a deactivated fused silica guard column ( $5 \mathrm{~m}$, Agilent, Santa Clara, USA) followed by a $30 \mathrm{~m} \times 0.25 \mathrm{~mm} \times 0.25 \mu \mathrm{m}$ fused silica column (DB-5MS, J\&W,

165 Santa Clara, USA). The GC was coupled to a mass selective detector (5977B Inert MSD, Agilent, Santa Clara, USA) operating in EI mode. Either 1 or $2 \mu \mathrm{L}$ of the final extract were injected into the column using a cool-on-column inlet $\left(80{ }^{\circ} \mathrm{C}\right.$ constant temperature) with a column flow rate of $1.0 \mathrm{~mL} / \mathrm{min}$. The $\mathrm{GC}$ oven program was modified to $80{ }^{\circ} \mathrm{C}$ initial temperature, hold for $1 \mathrm{~min}$, heated at a rate of $21^{\circ} \mathrm{C} \min ^{-1}$ to $150{ }^{\circ} \mathrm{C}, 5{ }^{\circ} \mathrm{C} \mathrm{min}{ }^{-1}$ to $300{ }^{\circ} \mathrm{C}$ and finally hold for $20 \min (54$ min total run time). The transfer line was kept at $300{ }^{\circ} \mathrm{C}$, while the MS quadrupole and ion source temperature were held at 170150 and $230{ }^{\circ} \mathrm{C}$, respectively. Molecular ions used for the identification are shown in Table S3c. 
Table 1: Target compounds and their acronyms.

\begin{tabular}{|c|c|c|c|}
\hline Compound & Acronym & Compound & Acronym \\
\hline $\begin{array}{l}\text { Polycyclic aromatic } \\
\text { hydrocarbons: }\end{array}$ & PAHs & 1,3-/2,10-/3,9-/3,10- Dimethylphenanthrene & $\begin{array}{l}\text { 1,3-/2,10-/3,9- } \\
/ 1,10-\mathrm{M}_{2} \mathrm{PHE}\end{array}$ \\
\hline Naphthalene & NAP & 1,6-/2,9- Dimethylphenanthrene & 1,6-/2,9- $\mathrm{M}_{2} \mathrm{PHE}$ \\
\hline Acenaphthylene & $\mathrm{ACY}$ & 1,7-Dimethylphenanthrene & $1,7-\mathrm{M}_{2} \mathrm{PHE}$ \\
\hline Acenaphthene & $\mathrm{ACE}$ & 2,3-Dimethylphenanthrene & 2,3- $\mathrm{M}_{2} \mathrm{PHE}$ \\
\hline Fluorene & FLN & 1,9-/4,9- Dimethylphenanthrene & 1,9-/4,9- $\mathrm{M}_{2} \mathrm{PHE}$ \\
\hline Phenanthrene & PHE & 1,8-Dimethylphenanthrene & $1,8-\mathrm{M}_{2} \mathrm{PHE}$ \\
\hline Anthracene & ANT & Retene (1-methyl-7-isopropylphenanthrene) & RET \\
\hline Fluoranthene & FLT & Oxygenated PAHs: & OPAHs \\
\hline Pyrene & PYR & 1,4-Naphthoquinone & 1,4- $\mathrm{O}_{2} \mathrm{NAP}$ \\
\hline Benzo(b)fluorene & $\mathrm{BBN}$ & Naphthalene-1-aldehyde & 1-(CHO)NAP \\
\hline Benzo(ghi)fluoranthene & BGF & 9-Fluorenone & 9-OFLN \\
\hline Cyclopenta(cd)pyrene & $\mathrm{CCP}$ & 9,10-Anthraquinone & $9,10-\mathrm{O}_{2} \mathrm{ANT}$ \\
\hline Benzo(a)anthracene & BAA & 1,4-Anthraquinone & $1,4-\mathrm{O}_{2} \mathrm{ANT}$ \\
\hline Triphenylene & $\mathrm{TPH}$ & 9,10-Phenanthrenequinone & $9,10-\mathrm{O}_{2} \mathrm{PHE}$ \\
\hline Chrysene & CHR & 11H-Benzo(a)fluoren-11-one & 11-OBaFLN \\
\hline Benzo(b)fluoranthene & $\mathrm{BBF}$ & 11H-Benzo(b)fluoren-11-one & $11-\mathrm{OBbFLN}$ \\
\hline Benzo(j)fluoranthene & BJF & Benzanthrone (7H-benz(de)anthracene-7-one) & BAN \\
\hline Benzo(k)fluoranthene & $\mathrm{BKF}$ & Benz(a)anthracene-7,12-dione & $7,12-\mathrm{O}_{2} \mathrm{BAA}$ \\
\hline Benzo(e)pyrene & BEP & 5,12-Naphthacenequinone & $5,12-\mathrm{O}_{2} \mathrm{NAC}$ \\
\hline Benzo(a)pyrene (benzo(def)chrysene) & BAP & Nitrated PAHs: & NPAHs \\
\hline Perylene & PER & 1-Nitronaphthalene & 1-NNAP \\
\hline Indeno(123-cd)pyrene & INP & 2-Nitronaphthalene & 2-NNAP \\
\hline Dibenz(ah)anthracene & DBA & 3-Nitroacenaphthene & 3-NACE \\
\hline Dibenz(ac)anthracene & DCA & 5-Nitroacenaphthene & 5-NACE \\
\hline Benzo(ghi)perylene & BPE & 2-Nitrofluorene & 2-NFLN \\
\hline Anthanthrene & ATT & 9-Nitroanthracene & 9-NANT \\
\hline Coronene & $\mathrm{COR}$ & 9-Nitrophenanthrene & 9-NPHE \\
\hline Benzonaphthothiophene & $\mathrm{BNT}$ & 3-Nitrophenanthrene & 3-NPHE \\
\hline Alkylated PAHs: & RPAHs & 2-Nitrofluoranthene & 2-NFLT \\
\hline 1-Methylphenanthrene & 1-MPHE & 1-Nitropyrene & 1-NPYR \\
\hline 2-Methylphenanthrene & 2-MPHE & 2-Nitropyrene & 2-NPYR \\
\hline 3-Methylphenanthrene & 3-MPHE & 7-Nitrobenzo(a)anthracene & 7-NBAA \\
\hline 4-Methylphenanthrene & 4-MPHE & 6-Nitrochrysene & 6-NCHR \\
\hline 3,6-Dimethylphenanthrene & $3,6-\mathrm{M}_{2} \mathrm{PHE}$ & 1,3-Dinitropyrene & $1,3-\mathrm{N}_{2} \mathrm{PYR}$ \\
\hline 2,6-Dimethylphenanthrene & $2,6-\mathrm{M}_{2} \mathrm{PHE}$ & 1,6-Dinitropyrene & $1,6-\mathrm{N}_{2} \mathrm{PYR}$ \\
\hline \multirow[t]{2}{*}{ 2,7-Dimethylphenanthrene } & $2,7-\mathrm{M}_{2} \mathrm{PHE}$ & 1,8-Dinitropyrene & $1,8-\mathrm{N}_{2} \mathrm{PYR}$ \\
\hline & & 6-Nitrobenzo(a)pyrene & 6-NBAP \\
\hline
\end{tabular}

\subsection{Supporting parameters}

175 Further description of analytical methods and other supporting parameters such as meteorological data, $\mathrm{PM}_{10}$ mass and concentrations of transition metals, elemental carbon (EC) and organic carbon (OC) can be found in the Supplement. The methods and the resulting data of other additional supporting parameters during the AQABA campaign used in this paper are reported in the following studies: a) The ship exhaust filter, black carbon (BC) and surface PAH concentrations as well as 
bypassing ships, potentially influencing the sampled air, in Celik et al. (2020), b) $\mathrm{O}_{3}$, nitrogen oxides $\left(\mathrm{NO}_{\mathrm{x}}\right.$, i.e. $\left.\mathrm{NO}+\mathrm{NO}_{2}\right)$ and $\mathrm{OH}$ radicals in Tadic et al. (2020), c) $\mathrm{O}_{3}, \mathrm{NO}_{2}$ and $\mathrm{SO}_{2}$ in Eger et al. (2019) and d) $\mathrm{NO}_{\mathrm{x}}$ and $\mathrm{NO}_{\mathrm{y}}$ (i.e. $\mathrm{NO}_{\mathrm{x}}+$ organic and inorganic oxides of nitrogen) in Friedrich et al. (2021). Measurements of $\mathrm{OH}$ radicals were done using the HydrOxyl Radical measurement $U$ nit based in fluorescence Spectroscopy (HORUS) instrument (Martinez et al., 2010; Hens et al., 2014), with the Inlet Pre-Injector (IPI) modification (Novelli, et al., 2014). The measurement of the actinic flux was done by a spectral radiometer as described in Meusel et al. (2016). The measurement of polychlorinated biphenyls (PCBs), hexachlorocyclohexanes (HCHs), dichlorodiphenyl-trichloroethane and isomers (DDX), other organochlorine pesticides (drins) was done similar to Lammel et al. (2016).

\subsection{Aerosol source apportionment}

Positive Matrix Factorization (EPA PMF 5.0) was applied to the $\mathrm{PM}_{10}$ chemical composition using the concentrations of OC, EC, BC and metals in both PMF groups and the sum of PCBs, HCHs, DDX, drins, PAHs, NPAHs and OPAHs only in group 1 and selected individual PAHs, OPAHs and NPAHs in group 2 to obtain source profiles and their contributions. All Digitel high-volume samples were considered in the PMF runs including those with contamination from the ship's stack. The data matrix was prepared in compliance with the procedure described by Polissar et al. (1998). The final matrices had 62 samples with 26 and 30 species in group 1 and 2, respectively.

To estimate the optimal number of sources, the PMF model was run several times with different model settings and 3 to 7 factors tested. The $\mathrm{Q}$ values ( $\mathrm{Q}_{\text {true }}, \mathrm{Q}_{\text {robust }}$ and $\mathrm{Q}_{\text {expected/theoretical }}$ ), the resulting source profiles, and the scaled residuals were examined. The optimum number of factors was chosen based on an adequate fit of the model to the data, as shown by the scaled residual histograms and physically interpretable results. The most stable solutions were found for 5 factors by extra modelling uncertainties of $26 \%$ and $19 \%$ for group 1 and group 2, respectively. All runs converged, the scale residuals were normally distributed and no swaps were observed with the displacement error analysis, indicating that there was limited rotational ambiguity (Table S9).

\subsection{Air mass origin}

Residence time distributions of air mass histories, 10 days backward in time, were studied using the FLEXPART Lagrangian particle dispersion model, with ECMWF meteorological data $\left(0.5^{\circ} \times 0.5^{\circ}\right.$, 3-hourly; Seibert and Frank, 2004; Stohl et al., 2005). The output is a measure of the time the computational particles (fictive air parcels) resided in grid cells. Per $24 \mathrm{~h}$ sampling time, 100000 particles were released at a height of $100 \mathrm{~m}$ a.s.l..

\subsection{Quality control}

More information about the analytical quality assurance such as the filtering of the samples against contamination by the own ship exhaust, the quality control of the analysis of the PAH derivatives (recoveries, blank correction, detection frequencies, limits of quantifications (LOQs)) and a summary of PMF diagnostics is given in the Supplement (Chapter S1.5). 


\section{Results and discussion}

\subsection{Occurrence of PAHs and PAH derivatives}

The average total (sum of gaseous and particulate phase) concentrations of the pollutants in the different sea regions are shown in Fig. 1. The average total concentrations (range in brackets) of the sum of one pollutant class from all high-volume air samples of the $\sum_{16} \mathrm{PAHs}, \sum_{27} \mathrm{PAHs}$ (including the S-heterocycle BNT), $\sum_{19} \mathrm{RPAHs}$ (range without RET), $\sum_{11} \mathrm{OPAHs}$ and

$\sum_{17} \mathrm{NPAHs}$ were $2.92 \pm 3.34(0.14-17.28) \mathrm{ng} \mathrm{m}^{-3}, 2.99 \pm 3.35(0.15-17.34) \mathrm{ng} \mathrm{m}^{-3}, 0.85 \pm 0.87$ (0.19-3.41) $\mathrm{ng} \mathrm{m}^{-3}, 0.24 \pm$ $0.25(0.04-1.42) \mathrm{ng} \mathrm{m}^{-3}$ and $4.34 \pm 7.37(0.69-46.50) \mathrm{pg} \mathrm{m}^{-3}$, respectively. All the data is filtered for contamination with the stack of our research vessel (details given in S1.5.1 in the Supplement). The detection frequencies of the compounds in the high-volume samples are shown in Fig. S1. All targeted PAHs, RPAHs and OPAHs were detected at least in one sample. From the 17 targeted NPAHs, 7 were detected in at least one high-volume sample. All total concentrations of the individual compounds and individual samples can be found in the Supplement, Tables S10-S14. Individual phases' concentrations are presented and discussed in a separate communication.

The spatial distribution of the concentrations of the different substance classes in both legs is shown in Fig. 2. The plot only shows the average concentration of each sampling stretch, which could also be impacted by individual local plumes at distinct times and locations. As visible in Figs. 1 and 2, the cleanest region, with the lowest concentration of all substance classes, was the Arabian Sea in the Indian Ocean. The average air concentrations (in brackets upper and lower estimate when using LOQ instead of LOQ/2 and 0 instead of LOQ/2, respectively) over the Arabian Sea were $0.59(0.57-0.61) \mathrm{ng} \mathrm{m}^{-3}, 0.59$ (no significant difference) $\mathrm{ng} \mathrm{m}^{-3}, 47.8(24.1-71.4) \mathrm{pg} \mathrm{m}^{-3}$ and $0.89(0.29-1.49) \mathrm{pg} \mathrm{m}^{-3}$ for the $\sum_{27} \mathrm{PAHs}, \sum_{19} \mathrm{RPAHs}$, $\sum_{11} \mathrm{OPAHs}$ and $\sum_{17} \mathrm{NPAHs}$, respectively. These concentrations are among the lowest ever reported levels of the PAHs and PAH derivatives. The air masses originated from the Indian Ocean and from parts of Somalia with no significant sources of PAHs or PAH derivatives (Fig. S3d). Similarly, findings from the same campaign for other air pollutants showed the lowest concentration over the Arabian Sea (Bourtsoukidis et al., 2019; Eger et al., 2019; Pfannerstill et al., 2019; Tadic et al., 2020; Wang et al., 2020). As shown in Fig. 2 a), c) and e), several samples in the Arabian Sea are missing in the first leg due to rejection as possibly contaminated by the stack of our research vessel Kommandor Iona (detailed overview of rejected samples and method description in Table S4 and Chapter S1.5.1, respectively). The Mediterranean Sea showed the highest average concentration of the $\sum_{27} \mathrm{PAHs}$ and $\sum_{11} \mathrm{OPAHs}$, i.e. $4.40 \mathrm{ng} \mathrm{m}^{-3}$ and $0.37 \mathrm{ng} \mathrm{m}^{-3}$, respectively. As illustrated in Fig. 2, the pollutant concentration over the Mediterranean Sea during the first leg differed from that of the second leg. The concentration of the $\sum_{27} \mathrm{PAHs}$ during the first leg $\left(2.20 \mathrm{ng} \mathrm{m}^{-3}\right)$ was significantly lower $(\mathrm{p}<0.05$, Student's t-test) than during the second leg $\left(5.18 \mathrm{ng} \mathrm{m}^{-3}\right)$. The difference was also significant $\left(\mathrm{p}<0.05\right.$, Student's t-test) for the $\sum_{11} \mathrm{OPAHs}$. The air mass histories (Fig. S2 and S3a) reveal that the difference is related to the different origin of the air masses. During the first leg, the sampled air predominantly originated from northern Africa and the western Mediterranean Sea, while during the second leg, the prevailing air masses came from north, transporting polluted air from large parts of Europe, including coastal areas and islands as also reported by Tadic et al. (2020). The northerly wind is a typical large-scale circulation pattern in summer 
over the Mediterranean Sea (Lelieveld et al., 2002). The highest concentrations of the PAH derivatives throughout the entire cruise were found in sample D58 in the Mediterranean Sea close to Sicily. The concentrations of $\sum_{11} \mathrm{OPAHs}$ and $\sum_{17} \mathrm{NPAHs}$ were $1.42 \mathrm{ng} \mathrm{m}^{-3}$ and $46.5 \mathrm{pg} \mathrm{m}^{-3}$, respectively. Sample D54, sampled $400 \mathrm{~km}$ south-east of Sicily, showed the highest concentration of the $\sum_{27} \mathrm{PAHs}$, especially of the low-molecular-weight PAHs (2-3-ring PAHs). These samples will be evaluated in more detail in Sect. 3.3.4.

The concentration of the $\sum_{17}$ NPAHs was similar during both legs in the Mediterranean Sea. On the one hand, 2-NFLT and 2NPYR were more abundant during the first leg, possibly due to higher secondary formation in aged air (Atkinson and Arey, 1994; Arey et al., 1986) On the other hand, the primarily emitted 1-NPYR (Atkinson and Arey, 1994) as well as 2-NNAP (having primary and secondary sources, Zhuo et al., 2017; Atkinson and Arey, 1994) had a higher concentration during the second leg. In contrast to the PAHs and OPAHs, the concentration of the $\sum_{19} \mathrm{RPAHs}$ in the air over the Mediterranean Sea was higher (not significant, $\mathrm{p}=0.14$, Student's t-test) and not lower during the first leg compared to the second leg. The different result for the RPAHs can firstly be explained by the different sampling intervals of the air sampler for the RPAHs (see Table S1). The RPAHs were not collected at the end of the campaign close to Sicily and Sardinia, where a high burden of PACs was measured. Second, north of Egypt in the Mediterranean Sea, close to the Suez Canal during the first leg, high concentrations of the MPHEs and $\mathrm{M}_{2}$ PHEs were found, possibly due to intense marine traffic concentrating or even queueing before entering into the Suez Canal.

The average concentration of the $\sum_{17} \mathrm{NPAHs}$ over the Mediterranean Sea was $5.23 \mathrm{pg} \mathrm{m}^{-3}$, which was slightly higher than the average concentration over the northern Red Sea $\left(4.52 \mathrm{pg} \mathrm{m}^{-3}\right)$ and the Gulf of Oman $\left(4.37 \mathrm{pg} \mathrm{m}^{-3}\right)$ but slightly lower than the average concentration over the Arabian Gulf $\left(6.65 \mathrm{pg} \mathrm{m}^{-3}\right)$. The concentration of the $\sum_{19} \mathrm{RPAHs}$ over the Mediterranean Sea $\left(0.81 \mathrm{ng} \mathrm{m}^{-3}\right)$ was similar to the Gulf of Oman $\left(0.83 \mathrm{ng} \mathrm{m}^{-3}\right)$ and lower than over the Arabian Gulf $\left(1.12 \mathrm{ng} \mathrm{m}^{-3}\right)$, too. Similar to the NPAHs and RPAHs, most other air pollutants (e.g. non-methane hydrocarbons, carbonyl compounds, $\mathrm{NO}_{\mathrm{x}}$, $\mathrm{NO}_{z}, \mathrm{O}_{3}, \mathrm{SO}_{2}$ ) measured during the AQABA campaign showed the highest concentration in the Arabian Gulf (Bourtsoukidis et al., 2019; Eger et al., 2019; Pfannerstill et al., 2019; Tadic et al., 2020; Wang et al., 2020; Friedrich et al., 2021).

The concentration of the $\sum_{17} \mathrm{NPAHs}$ over the southern Red Sea was $1.68 \mathrm{pg} \mathrm{m}^{-3}$. Similar as for the $\sum_{17} \mathrm{NPAHs}$, the southern Red Sea was the region with the second lowest concentrations of the $\sum_{27} \mathrm{PAHs}$ and the $\sum_{11} \mathrm{OPAHs}\left(0.94 \mathrm{ng} \mathrm{m}^{-3}\right.$ and $88.3 \mathrm{pg}$ $\mathrm{m}^{-3}$, respectively). The pollutant burden was low since the air was predominantly coming from eastern Africa, mainly from Sudan, Eritrea and western and southern parts of Egypt (Fig. S3c), areas with low population and industrial emitter densities. Air over the northern Red Sea, including the Suez Canal, is more polluted owing to the dense shipping traffic in the canal (Bourtsoukidis et al., 2019), the vicinity of the megacity Cairo and the densely populated and urbanised Nile Delta. The total concentration of the $\sum_{19}$ RPAHs over the northern Red Sea was $0.93 \mathrm{ng} \mathrm{m}^{-3}$. The highest concentration was measured in air close to Jeddah, which was almost one order of magnitude higher polluted than the other samples.

As shown in Fig. 1, the Gulf of Oman and the Arabian Gulf were similarly polluted as the northern Red Sea. The 275 concentrations of the $\sum_{27} \mathrm{PAHs}$ and the $\sum_{11} \mathrm{OPAHs}$ were higher (but not significantly according to Student's t-test) in the Arabian Gulf $\left(2.8 \mathrm{ng} \mathrm{m}^{-3}\right.$ and $181 \mathrm{pg} \mathrm{m}^{-3}$, respectively) compared to the Gulf of Oman $\left(2.0 \mathrm{ng} \mathrm{m}^{-3}\right.$ and $161 \mathrm{pg} \mathrm{m}^{-3}$, 
respectively). The air masses sampled in the Gulf of Oman were mainly transported from Oman, United Arab Emirates, Iran and the Arabian Sea (Fig S3e). The predominant wind direction in the Arabian Gulf during the first leg was northwest transporting air from Qatar, Bahrain, Kuwait and Iraq (Fig S3f, 28-30 July 2017), while during the second leg, the wind changed to northeast, increasing the contribution of air advected from Iran (Fig. S3f, 4-6 August 2017). A significantly higher ( $\mathrm{p}<0.05$, Student's t-test) concentration of the $\sum_{27} \mathrm{PAHs}$ prevailed during advection from northeast (second leg, 3.53 $\mathrm{ng} \mathrm{m}^{-3}$ ) than from northwest (first leg, $1.69 \mathrm{ng} \mathrm{m}^{-3}$ ).

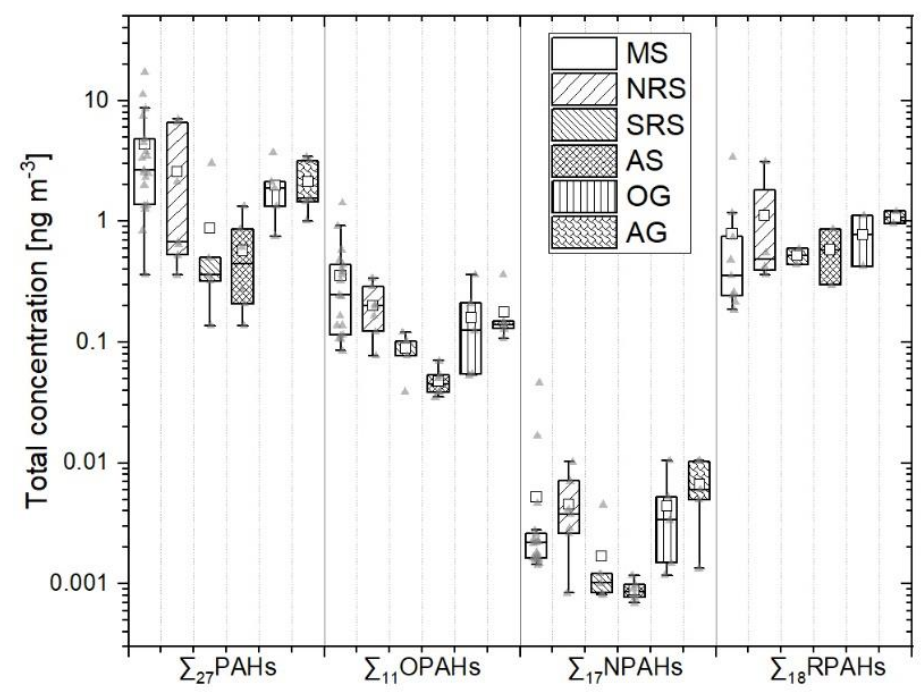

Figure 1: Total concentration (gas + particulate phase) of PAC groups across sea regions (MS: Mediterranean Sea; NRS: northern Red Sea; SRS: southern Red Sea; AS: Arabian Sea; OG: Gulf of Oman; AG: Arabian Gulf; Empty square: mean value; Grey triangles: Measurement points (difficult to see within the boxed); Box with additional borders: interquartile range (IQR) bound by the $75^{\text {th }}$ and $25^{\text {th }}$ percentile and range of $1.5 \mathrm{IQR}$; Horizontal line: Median).
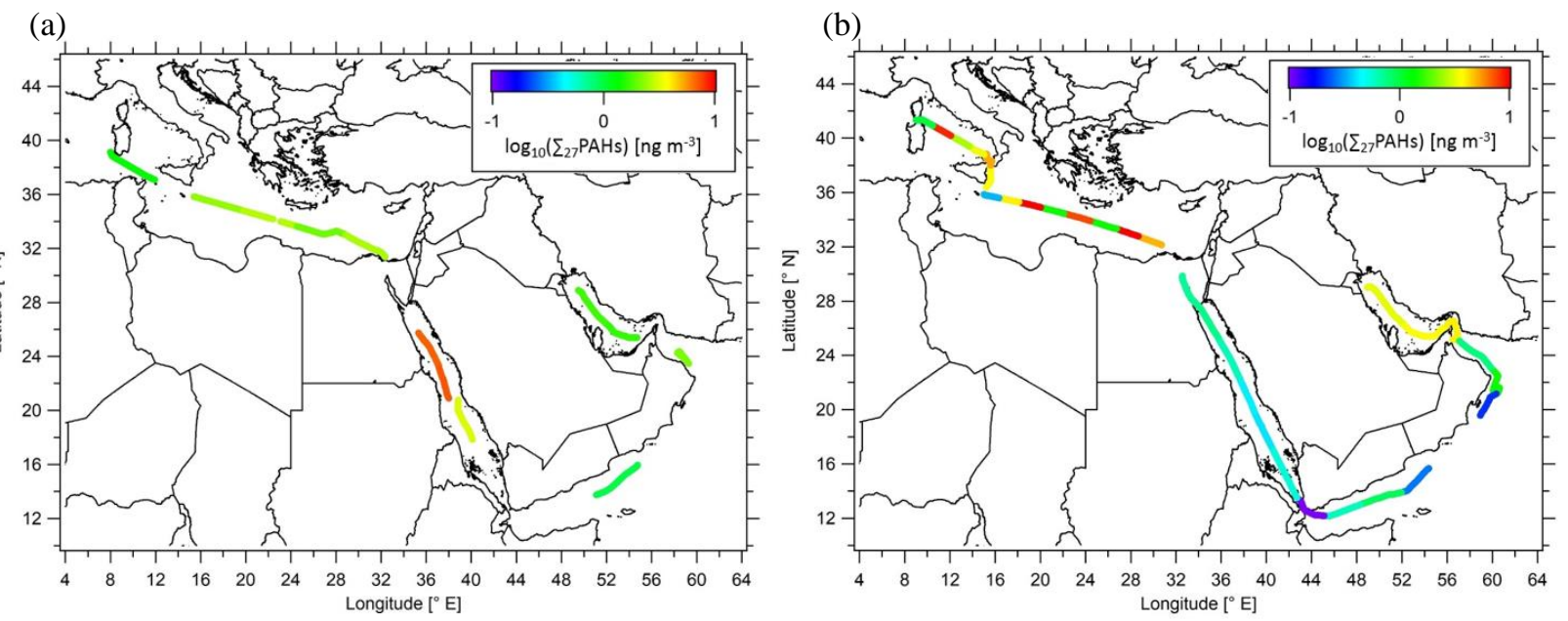

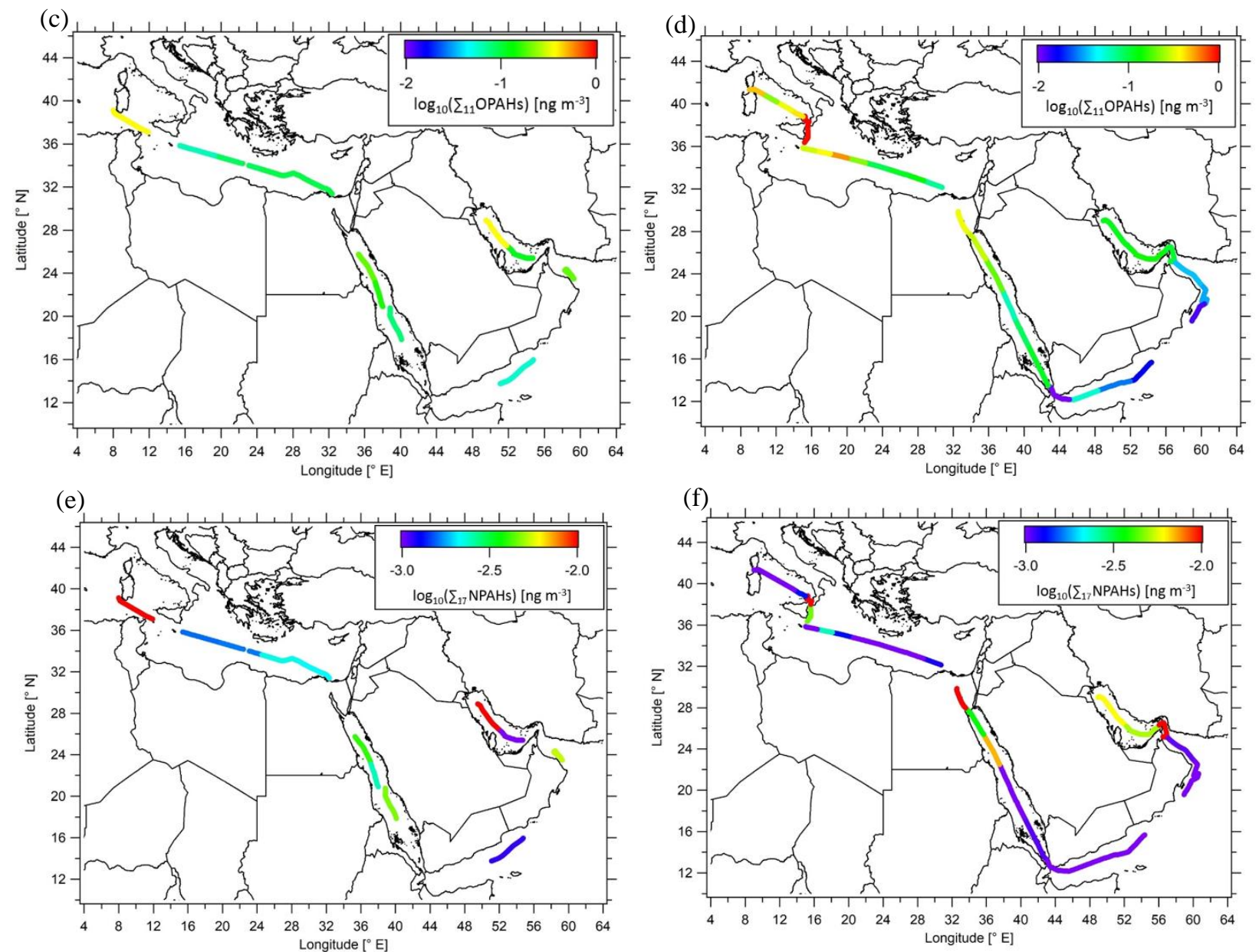

Figure 2: Total concentration (logarithmic scale) of $\sum_{27}$ PAHs, in (a) and (b), $\sum_{11} \mathrm{OPAHs}$ in (c) and (d) and $\sum_{17} \mathrm{NPAHs}$ in (e) and (f) during the first leg in (a), (c), (e) and the second leg in (b), (d), (f). Spatial resolution of data limited to sampling stretches (see Fig. S1).

The concentrations of the PAH derivatives in a few samples in the remote sea regions were among the lowest ever reported,

while other samples reached concentration levels previously found at suburban sites. The samples from near Sicily and Sardinia in the Mediterranean Sea, near the Suez Canal and over the Gulfs showed a total concentration of 0.1-1.4 $\mathrm{ng}^{-3}$ and 1.2-47 $\mathrm{pg} \mathrm{m}^{-3}$ for the $\sum_{11} \mathrm{OPAHs}$ and $\sum_{17} \mathrm{NPAHs}$, respectively. The concentrations of the individual substances are similar to air samples from a rural and an urban site in Chile (Scipioni et al., 2012), a rural site in France (Albinet et al., 2007), a suburban site in the USA (Bamford and Baker, 2003) and a background site in the Czech Republic (Nežiková et al., 2021). NPAHs and OPAHs have rarely been examined in the marine environment. A study by Lammel et al. (2017) investigated the 3-4-ring NPAHs in the eastern Mediterranean under the influence of long-range transport from central and eastern Europe in summer 2012. The concentration of the $\sum_{11} 3$-4-ring NPAHs $\left(23.7 \mathrm{pg} \mathrm{m}^{-3}\right)$ was one order of magnitude higher than the concentration of the sum of the same NPAHs in the Mediterranean Sea in our study $\left(2.75 \mathrm{pg} \mathrm{m}^{-3}\right)$. The concentration of the 
samples with the lowest urban influence, found by Lammel and colleagues, were closer to our observed concentrations. In contrast to the NPAHs, the concentration of the $\sum_{6} 4$-ring PAHs was in the same order of magnitude. Lammel and colleagues found $426 \mathrm{pg} \mathrm{m}^{-3}$ as average of all samples and $284 \mathrm{pg} \mathrm{m}^{-3}$ as average of the samples with the lowest urban influence, while we determined a concentration of $366 \mathrm{pg} \mathrm{m}^{-3}$ for the sum of the same PAHs. From the same study, Lammel et al. measured 1-NPYR, 2-NFLT and 2-NPYR in marine background air being $0.21,1.68$ and $0.92 \mathrm{pg} \mathrm{m}^{-3}$, whereas respective concentrations were $0.42,0.93$ and $0.069 \mathrm{pg} \mathrm{m}^{-3}$ in air over the whole transect of the Mediterranean Sea of our campaign.

The lower levels of secondarily formed 2-NFLT and 2-NPYR can be explained by significant long-range transport from $\mathrm{NO}_{\mathrm{x}}$ poor areas, notably northern Africa during the first leg. One decade earlier, in the eastern Mediterranean Sea in summer 2001, Tsapakis and Stephanou (2007) report approximately one order of magnitude higher values, i.e. 29 and $21 \mathrm{pg} \mathrm{m}^{-3}$ for 2-NFLT and 2-NPYR, respectively. Furthermore, they determined 9,10- $\mathrm{O}_{2} \mathrm{ANT}$ and 9-OFLN (34.2 and $46.3 \mathrm{pg} \mathrm{m}^{-3}$, respectively), which was in the same range as our measurements in the Mediterranean Sea with 95.4 and $36.2 \mathrm{pg} \mathrm{m}^{-3}$, 315 respectively.

The concentrations of NPAHs (40, 90 and $60 \mathrm{pg} \mathrm{m}^{-3}$ for 1-NPYR, 2-NFLT and 2-NPYR, respectively) in source regions of the Mediterranean such as Athens (Marino et al., 2000) were approximately three orders of magnitude higher than those in our study over the Mediterranean Sea. This urban to marine background gradient is a lot smaller for the OPAHs compared to the NPAHs. In summer 2013, Alves et al. (2017) found at a suburban site in Athens an air concentration of 9, 28 and 242 pg $\mathrm{m}^{-3}$ for $9,10-\mathrm{O}_{2} \mathrm{ANT}, 9-\mathrm{OFLN}$ and BAN, respectively. This is one order of magnitude lower for 9,10- $\mathrm{O}_{2} \mathrm{ANT}$, the same magnitude for 9-OFLN and one order of magnitude higher for BAN compared to our results in the Mediterranean Sea. This suggests longer lifetimes or higher formation rates of OPAHs than NPAHs.

Harrison et al. (2016) measured PAHs and its derivatives at three sites along the east coast of the Red Sea, in a plume of a major point source (petrochemical complex). 9,10- $\mathrm{O}_{2}$ ANT had a concentration between 3.15 and $4.02 \mathrm{ng} \mathrm{m}^{-3}$, which is two orders of magnitude higher than in the particulate phase of samples over the northern Red Sea in our study. The concentration of 5,12- $\mathrm{O}_{2} \mathrm{NAC}$ was between one and two orders of magnitude higher, while the difference was smaller for 7,12- $\mathrm{O}_{2}$ BAA. The difference of the individual NPAHs concentrations between the measurements at the coast from Harrison et al. and our measurements offshore is even more pronounced. The concentrations of 2-NNAP, 2-NFLT, 1-NPYR, 2-NPYR and 7-NBAA were over three orders of magnitude higher in the plume measured by Harrison and colleagues. In contrast, the PAH concentration was almost similar (for low-molecular-weight PAHs) or only one order of magnitude higher (for highmolecular-weight PAHs, i.e. 5-7-ring PAHs) onshore. This, again, points to short atmospheric lifetimes of NPAHs. The OH reaction rate coefficients of PAHs and NPAHs are similar (Table S2, US EPA, 2019), but NPAHs are more prone to photolysis (Fan et al., 1996; Keyte et al., 2013; Wilson et al., 2020). This is furthermore supported by findings that the NPAH/PAH ratios in mid-latitudes are higher in winter than in summer, obviously since the photochemical sink of NPAHs 335 in summer overcompensates the higher formation potential as a source of NPAHs (Nežiková et al., 2021). Nassar et al. (2011) measured PAHs and two NPAHs in the area of Greater Cairo. The concentration of 1-NPYR in the study was around one order of magnitude higher than that in the air measured on the ship over the Suez Canal. In contrast, the concentration of 
the low-molecular-weight PAHs was in the same range, while the concentrations of high-molecular-weight PAHs offshore were one or more orders of magnitude lower.

340 Few studies report MPHE and $\mathrm{M}_{2}$ PHE in the coastal marine atmosphere, the open sea, background and urban sites. Tsapakis and Stephanou (2005) analysed atmospheric samples collected offshore over the eastern Mediterranean Sea and at a background station in north-eastern Crete (Greece) and reported total (gas and particulate phase) concentrations for $\sum$ MPHE of $13.6 \mathrm{ng} \mathrm{m}^{-3}$ and for $\sum \mathrm{M}_{2} \mathrm{PHE}$ of $6.5 \mathrm{ng} \mathrm{m}^{-3}$, respectively. Mandalakis et al. (2002) reported gas and particulate phase concentrations of $6.07 \mathrm{ng} \mathrm{m}^{-3}$ and $3.17 \mathrm{ng} \mathrm{m}^{-3}$ for $\sum$ MPHE and $\sum \mathrm{M}_{2} \mathrm{PHE}$, respectively, in the Saronikos Gulf, which is

345 impacted by busy marine traffic and the shipyard industry along the coast (Valavanidis et al., 2008). In the same study, corresponding concentrations of $6.95 \mathrm{ng} \mathrm{m}^{-3}$ for $\sum \mathrm{MPHE}$ and of $4.17 \mathrm{ng} \mathrm{m}^{-3}$ for $\sum \mathrm{M}_{2} \mathrm{PHE}$ were reported for the urban atmosphere of Athens, and respectively $0.52 \mathrm{ng} \mathrm{m}^{-3}$ and $0.34 \mathrm{ng} \mathrm{m}^{-3}$ for the background urban agglomeration. The concentrations in our study were comparably to the background concentrations, i.e. $0.51 \mathrm{ng} \mathrm{m}^{-3}$ and $0.33 \mathrm{ng} \mathrm{m}^{-3}$ for $\sum \mathrm{MPHE}$ and $\sum \mathrm{M}_{2} \mathrm{PHE}$, respectively.

350 The results of the $\sum$ MPHE in the gas phase $\left(0.47 \mathrm{ng} \mathrm{m}^{-3}\right)$ in our study are also comparable to concentrations over the southeastern Mediterranean Sea and the Aegean Sea measured by Castro-Jiménez et al. (2012), i.e. $0.58 \mathrm{ng} \mathrm{m}^{-3}$ and $0.61 \mathrm{ng} \mathrm{m}^{-3}$, respectively, but lower than over the western Mediterranean Sea, the Ionian Sea and the Black Sea. On an Atlantic Ocean transect from the Netherlands to South Africa, concentrations of 1-MPHE as low as $0.022 \mathrm{ng} \mathrm{m}^{-3}$ were reported, compared to $0.45 \mathrm{ng} \mathrm{m}^{-3}$ for samples taken closer to Europe and western Africa (Jaward et al., 2004). In our study 1-MPHE ranged 355 between 0.026 and $0.49 \mathrm{ng} \mathrm{m}^{-3}$.

\subsection{Composition patterns}

(a)

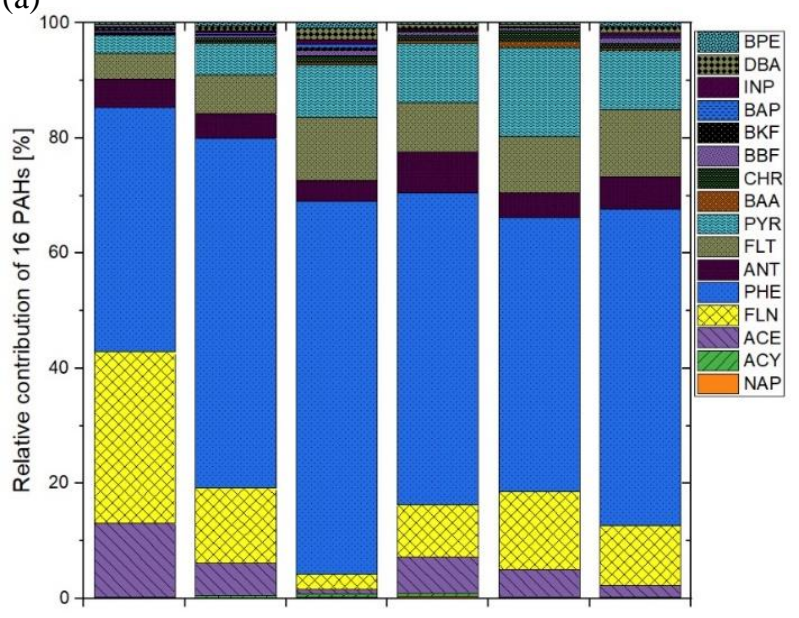

(b)

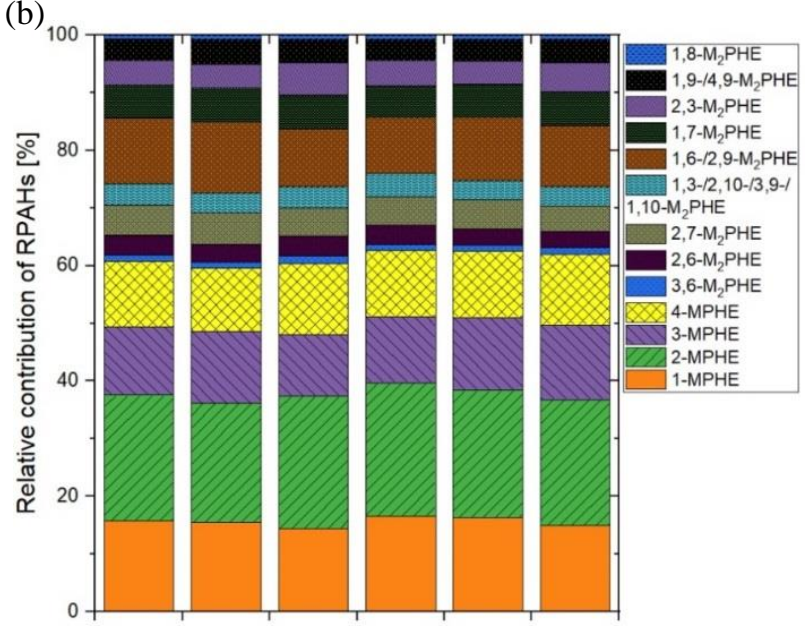


(c)

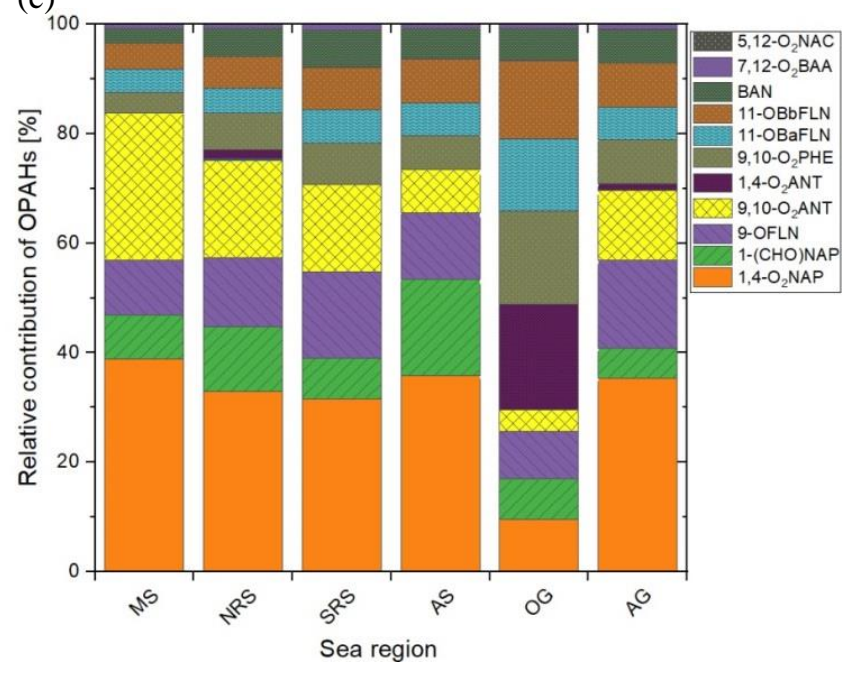

(d)

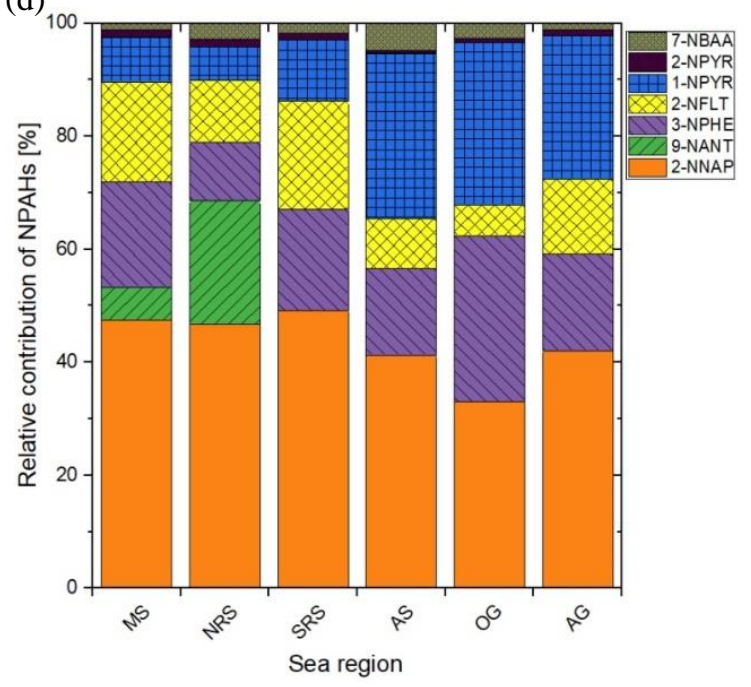

360 Figure 3: Relative amount of (a) 16 EPA-PAHs, (b) RPAHs, (c) OPAHs, (d) NPAHs across sea regions (MS: Mediterranean Sea; NRS: northern Red Sea; SRS: southern Red Sea; AS: Arabian Sea; OG: Gulf of Oman; AG: Arabian Gulf). Full names of the substances are given in Sects. 2.3.1, 2.3.2 and Tables 1 and S2.

\subsubsection{PAHs}

The substance patterns of PAHs in the six different sea regions are shown in Fig. 3a. PHE was by far the most abundant

PAH in all regions (average contribution of $49 \%$ ), followed by FLN, ACE, FLT and PYR with average contributions of 24 $\%, 10 \%, 6 \%$ and $5 \%$, respectively. It can be noted that the PAH composition patterns were similar in all regions. However, the patterns of the Mediterranean Sea and the southern Red Sea differed from the other regions. The contribution of PHE in the southern Red Sea was higher than the average, while it was lower than the average in the Mediterranean Sea. The opposite could be observed for FLN. The different pattern in the Mediterranean Sea was mainly caused by the samples from the second leg with high influence of aerosols from Europe.

\subsubsection{RPAHs}

The distribution pattern of RPAHs among the campaign regions is presented in Fig. 3b. The RPAHs did not show significant regional differences in the composition pattern. 2-MPHE, 1-MPHE and 3-MPHE were the most abundant alkylated PAH species throughout the campaign, making up $22 \%, 16 \%$ and $12 \%$ of the total RPAHs measured. Among the $\mathrm{M}_{2}$ PHEs, 1,6and 2,9- $\mathrm{M}_{2} \mathrm{PHE}$ were the most abundant compounds.

\subsubsection{OPAHs}

As shown in Fig. 3c, the regional differences between the OPAH composition patterns are more pronounced than the regional average PAH and RPAH patterns. 1,4- $\mathrm{O}_{2} \mathrm{NAP}, 9,10-\mathrm{O}_{2}$ ANT and 9-OFLN were the most abundant OPAHs, with an average contribution of $35 \%, 22 \%$ and $11 \%$, respectively. The high share of 9,10-O $\mathrm{O}_{2}$ ANT and 9-OFLN was also found at 
several continental sites (Albinet et al., 2007; 2008; Li et al., 2015; Wei et al., 2015; Drotikova et al., 2020; Lammel et al., 2020; Jariyasopit et al., 2021; Nežiková et al., 2021). In several of these papers, 1,4- $\mathrm{O}_{2} \mathrm{NAP}$ was not measured. Nežiková et al. (2021) and Jariyasopit et al. (2021) only found small relative amounts of 1,4- $\mathrm{O}_{2} \mathrm{NAP}$ at the continental background site Košetice and in the Athabasca oil sands region in Canada, respectively. In contrast, Wei et al. (2015) and Lammel et al. (2020) found relatively high contributions to the total amount of OPAHs at urban sites in China and in the Czech Republic, respectively. Bandowe et al. (2014) observed higher concentrations of 1,4- $\mathrm{O}_{2} \mathrm{NAP}$ in summer in $\mathrm{PM}_{2.5}$ compared to the cold season, although the partitioning of the compound will be shifted to the gas phase in summer. This would lead to lower concentrations in summer since the degradation rates of most PACs are expected to be higher in the gas phase (Feilberg et al., 1999; Keyte et al., 2013). They hypothesized that 1,4- $\mathrm{O}_{2} \mathrm{NAP}$ is significantly formed by secondary formation, as also shown by Kautzman et al. (2010) and Keyte et al. (2013). This can be supported by the low winter to summer ratio of 1,4$\mathrm{O}_{2}$ NAP despite higher emissions in winter at Košetice (Nežiková et al., 2021). High secondary formation in plumes especially in the Mediterranean Sea and the Arabian Gulf (as explained in Sect. 3.3.4), as well as low reaction rates for the degradation of 1,4- $\mathrm{O}_{2} \mathrm{NAP}$ compared to all other OPAHs (Table S2, Atkinson et al., 1989) might explain the high relative contribution of this quinone in our study. Except for the samples from the Gulf of Oman, 1,4- $\mathrm{O}_{2} \mathrm{NAP}$ always had the highest contribution of $25-40 \%$. This quinone is frequently reported having a high ability to produce reactive oxygen species (Charrier and Anastasio, 2012; Verma et al., 2015).

In the Gulf of Oman, the contribution from high-molecular-weight OPAHs (4-ring OPAHs) was higher compared to the other regions. The composition pattern of the samples from the Arabian Sea differed from the other samples because of a lower share of 9,10- $\mathrm{O}_{2} \mathrm{ANT}$ and a higher share of 1-(CHO)NAP. The same was true for the samples of the first leg in the Mediterranean Sea (see Table S16). 1-(CHO)NAP has been reported prominent among OPAHs from urban and other polluted sites, but not generally (Albinet et al., 2007; 2008 (partly); Wei et al., 2015; Tomaz et al., 2016; Lammel et al., 2020 (in Kladno)).

\subsubsection{NPAHs}

Similar to the OPAHs, the regional differences in the NPAH composition pattern are more pronounced than the PAH and RPAH patterns. As illustrated in Fig. 3d, the most abundant NPAHs were 2-NNAP, 3-NPHE, 2-NFLT and 1-NPYR, with an 405 average contribution of $45 \%, 18 \%, 15 \%$ and $12 \%$, respectively. The contribution of 2-NNAP ranged between one third and half in all regions. However, it was not detected above LOQ in the gas phase of samples from the Arabian Sea. Due to the total detection frequency of $>30 \%$, the values were replaced by LOQ/2 what could lead to an overestimation in this case. A large fractional contribution of NNAPs, 3-NPHE and 2-NFLT was also found by Lammel et al. (2017) in the eastern Mediterranean Sea. At the continental site in the study from Lammel et al., as well as in other previous studies at continental 410 sites, 2-NFLT, 9-NANT and 1-NNAP were the most abundant NPAHs (Bamford and Baker et al., 2003; Albinet et al., 2007; 2008; Tomaz et al., 2016; Drotikova et al., 2020; Lammel et al., 2020; Nežiková et al., 2021). In our study, 9-NANT had a significant contribution only in the northern Red Sea. We found only a few samples with 9-NANT >LOQ (LOQs in Table 
S6c). The reason for the low contribution during the entire campaign might be the relatively high LOQ compared to other NPAHs (Table S6c) or that 9-NANT is prone to photolysis, which could have been high in this campaign because of high solar irradiation. The significance of photodegradation of 9-NANT is also supported by lower contributions in summer compared to the cold season, as found by Tomaz et al. (2016) and Nežiková et al. (2021). However, it can also be caused by seasonal variation in the emission sources or a higher degradation rate in the gas phase based on the significantly lower particulate fraction in summer (Tomaz et al., 2016; Nežiková et al., 2021). The same might be true for 1-NNAP. In contrast to our campaign, several other studies found significant amounts of 1-NNAP in air samples at mid-latitude but continental sites (Bamford and Baker et al., 2003; Albinet et al., 2007; 2008; Tomaz et al., 2016; Drotikova et al., 2020, Lammel et al., 2020; Nežiková et al., 2021). The low contribution of 1-NNAP in air over the Mediterranean and around the Arabian Peninsula could also be due to the relatively high LOQ in PUFs (Table S6c) or the photodegradation of 1-NNAP, which is faster than of 2-NNAP, as described by Feilberg et al. (1999). We hypothesize that the comparably low rate constants for the photodegradation as well as for the reaction with OH (Table S2, US EPA, 2019) are one reason for the high relative contribution of 2-NNAP. 2-NNAP is frequently detected in continental sites but mostly with lower relative contributions than 1-NNAP, 9-NANT and 2-NFLT (Bamford and Baker et al., 2003; Albinet et al., 2007; 2008; Tomaz et al., 2016; Drotikova et al., 2020, Lammel et al., 2020; Nežiková et al., 2021). Only at a remote site in Chile, 2-NNAP was also found to have a very high relative contribution, which was explained by direct emissions or transport assuming a long atmospheric lifetime (Scipioni et al., 2012). The resistance to photochemical degradation can also be supported by the finding from Nežiková et al. (2021) that the relative contribution of 2-NNAP is higher in summer than in winter. However, this can also be due to different emission sources or stronger secondary formation in summer (Zhuo et al., 2017).

The fractional contribution of 1-NPYR is high in the Gulf of Oman and the Arabian Gulf. This can be explained by a significant amount of 1-NPYR in the exhaust of fossil fuel combustion (IARC, 2018; Zhao et al., 2015) and its high abundance near petrochemical industries (Caumo et al., 2018). It is used as a marker for primary emissions since it does not have significant secondary sources (Arey et al., 1986). The relatively short estimated lifetime of 1-NPYR in air due to photodegradation (Feilberg and Nielsen, 2000) and the small reaction rate with OH (Table S2, US EPA, 2019) could explain its low contribution in the Mediterranean Sea, since we sampled relatively aged air samples in that region. The relatively high contribution of 1-NPYR in the Arabian Sea might be due to bypassing ships (Table S18) as we found 1-NPYR highly abundant in the ship exhaust (Sect. 3.3.1). The high contribution of 1-NPYR in samples D40-42, in or close to the Gulf of Aden, is possibly due to pollution from coastal cities in the northeastern province of Somalia. The continental influence of these samples is also shown in the results of the PMF analysis (Fig. 4b). The large contribution of long-range transported aerosols in the Mediterranean Sea is also illustrated by the high contribution of 2-NFLT, which is formed in secondary processes (Arey et al., 1986). The contribution of 2-NFLT is also high in the southern Red Sea and the Arabian Sea, two regions with minor influence of primary emissions but higher fraction of long-range transported aerosols. 3-NPHE, which 445 has primary and secondary sources (Atkinson and Arey, 1994; Heeb et al., 2008; Ringuet et al., 2012a), has an almost similar contribution in all regions. This could be explained by various different sources or a long mean atmospheric lifetime. 


\subsection{Source apportionment}

\subsubsection{Sources of PAH derivatives by PMF}

As shown in Figs. 4 and S4 as well as described in the Supplement (Chapter S2.4.1), the PMF analysis, revealed five different source factors, namely fresh and aged shipping emissions, continental emissions, residual oil combustion and desert dust.

The PAHs, NPAHs and OPAHs in the air over the Mediterranean Sea and in the seas around the Arabian Peninsula are believed to originate primarily from fresh and aged shipping emissions. Fresh shipping emissions, mainly from the ship stack of our research vessel Kommandor Iona, were predominantly apparent during the first leg due to the prevailing wind direction. Aged shipping emissions contributed to air pollution mainly in regions with congested marine routes such as the Suez Canal (4 July 2017 and 20-23 August 2017), the Bab al-Mandab Strait near Djibouti (16-17 July 2017) and the Strait of Hormuz, especially near Fujairah (26-28 July 2017 and 5-6 August 2017). The amount of bypassing ships, potentially influencing the sampled air, based on the data from Celik et al. (2020), is given in Table S18.

Another important source of PAH derivatives were continental emissions. Based on the distribution of residence times of air masses during these sampling times, we could conclude that these emissions mainly came from Europe (especially received in the Mediterranean Sea, but also in the Arabian Gulf), countries around the Arabian Gulf (mainly received there) and Egypt (mainly received in the northern Red Sea). Furthermore, the PACs originated from residual oil combustion. High factor contributions (Figs. 4b and S4b) in the period between 24 July and 6 August 2017 were linked to the samples collected in the Gulf of Oman and the Arabian Gulf and influenced by the emissions in the coastal areas and offshore (Fig. S3e and f) as also reported by Bourtsoukidis et al. (2019), Eger et al. (2019), Pfannerstill et al. (2019) and Wang et al. (2020). The source factor identified with minimum contributions of NPAH and OPAHs was desert dust. The finding of PAH derivatives in the factor desert dust could be explained by mixing of dust with other emissions sources such as continental pollution or shipping emissions. The concentration of the factor desert dust peaked primarily during a period of Sahara dust outbreaks (from 13-18 July 2017), while samples were collected over the Red Sea and over the western part of the Gulf of Aden (Fig. S3c and d, see also Eger et al. (2019)). Dust emitted on the Arabian Peninsula is evident during the sail in the Gulf of Oman and the Arabian Gulf (24 July and 6 August 2017, Fig. S3d and e) but mixed with several other sources.

The contribution of the individual OPAHs and NPAHs can be seen in PMF group 2 in Figs. 4 and 5, showing the relative contributions of each factor to the concentration of each substance. All PACs targeted in the PMF run (group 2) had a significant contribution from fresh shipping emissions as their source. Moreover, by comparing several samples with a significant influence of the exhaust from the own stack (samples D16; 17; 20; 22; 23; 28; 37; 38; see Table S4 and Fig. S4) to the stack filtered regional average concentrations, we could show that almost all detected PAHs, NPAHs and OPAHs were elevated in the samples with fresh shipping emissions (Table S17). 1-NPYR showed the highest ratio of contaminated to filtered samples among the NPAHs, while 11-OBaFLN and 1-(CHO)NAP had the highest ratio among the OPAHs. All targeted OPAHs showed a ratio higher than 1. For the NPAHs, only 2-NFLT was not elevated except for a ratio of 5 in the 
Arabian Sea. 2-NFLT had been reported to be present in diesel particulate matter (Bamford et al., 2003; Zimmermann et al., 2012). However, this was explained by the gas phase formation of 2-NFLT after emission during sample collection. Surprisingly, the concentration of 2-NPYR was significantly elevated in the fresh shipping emissions. This is unexpected, as 2-NPYR was reported absent in diesel exhaust (Bamford et al., 2003) and believed to be formed through secondary formation only (Finlayson-Pitts and Pitts, 1999; Wilson et al., 2020). Zhao et al. (2019; 2020) found significant amounts of

485 2-NPYR in ship exhaust gas depending on the fuel type and the engine loading. They report high emissions of this compound, especially with heavy fuel oil use and mainly under low engine speeds. The abundance of 2-NPYR was explained by secondary formation due to higher $\mathrm{NO}_{\mathrm{x}}$ emissions and higher residence times during these conditions. The results from Zhao et al. $(2019 ; 2020)$ and from our study suggest a very high formation rate of 2-NPYR. According to Keyte et al. (2013) and Wilson et al. (2020), the reaction rate constant of PYR with OH is five times higher for 2-NPYR compared

490 to 2-NFLT but the yield of 2-NPYR is lower.

The large contribution of aged shipping emissions to the concentration of 2-NFLT and 2-NPYR (Fig. 5) illustrates the importance of secondary formation of these two NPAHs. In contrast, 1-NPYR is not abundant in the aged shipping emissions showing that there is no significant secondary formation. It has been reported that 1-NPYR arises solely from primary emissions (Bezabeh et al., 2003; Reisen and Arey, 2005). The contribution of aged shipping emissions to the occurrence of 3-NPHE could either be explained by the higher atmospheric half-life of $79 \mathrm{~h}$ compared to 2-NFLT, 1-NPYR and 2-NPYR (Table S2, US EPA, 2019) or by secondary formation as previously suggested (Tomaz et al., 2017). All detected OPAHs were abundant in the aged shipping emissions. Their abundance points to a long lifetime or formation in the atmosphere. The relative contributions of $11-\mathrm{OBaFLN}$, BAN and 7,12- $\mathrm{O}_{2} \mathrm{BAA}$ were relatively small (Fig. 5). For 5,12$\mathrm{O}_{2} \mathrm{NAC}$ and 1,4- $\mathrm{O}_{2} \mathrm{NAP}$, the contribution of aged shipping emissions was higher. It was previously reported that from the

500 measured OPAHs, 1,4- $\mathrm{O}_{2} \mathrm{NAP}, 1-(\mathrm{CHO}) \mathrm{NAP}, 9-\mathrm{OFLN}, 9,10-\mathrm{O}_{2} \mathrm{ANT}, 1,4-\mathrm{O}_{2} \mathrm{ANT}, 9,10-\mathrm{O}_{2} \mathrm{PHE}$, 11-OBaFLN and 7,12$\mathrm{O}_{2}$ BAA can be formed from the reaction of parent-PAHs with oxidants (Helmig and Harger, 1994; Perraudin et al., 2007; Wang et al., 2007; Gao et al., 2009; Ringuet et al., 2012a; Keyte et al., 2013; Dang et al., 2015). Based on the previous findings from literature and the results of the PM factor "aged shipping emissions", a contribution from secondary formation to the burden of 1,4- $\mathrm{O}_{2} \mathrm{NAP}$ and 7,12- $\mathrm{O}_{2} \mathrm{BAA}$ is likely, in addition to the known secondarily formed substances 2-NPYR and

505 2-NFLT. Since BAN and 11-OBaFLN have not been found as secondary formation products but highly abundant in primary emissions (Albinet et al., 2007; Ringuet et al., 2012a; Clergé et al., 2019), we hypothesize that their contribution to aged shipping emissions is only due to their atmospheric lifetime. Since the primary emitted 1-NPYR is not abundant in aged shipping emissions, it shows that BAN and 11-OBaFLN have a higher atmospheric lifetime than 1-NPYR. Since the estimated lifetime due to oxidation by OH is higher for 1-NPYR than for the two OPAHs (Table S2, US EPA, 2019),

510 degradation of 1-NPYR is expected to be governed by photodegradation (Feilberg and Nielsen) as already mentioned in Sect. 3.2.4. Since there is not much data in the literature about 5,12- $\mathrm{O}_{2} \mathrm{NAC}$, it's abundance in aged shipping emissions can either be due to high atmospheric lifetime or secondary formation. 
1-NPYR and 3-NPHE seem to be good tracers for oil combustion, hence the correlation with emissions from the petrochemical industry in the Gulf of Oman and the Arabian Gulf. 1-NPYR and 3-NPHE are known to be emitted during combustion of oil (Streibel et al., 2017). In addition, all OPAHs included into the PMF, except for 1,4-O $\mathrm{O}_{2} \mathrm{NAP}$, originated directly or secondarily from residual oil combustion.

Except for 11-OBaFLN, all considered PAHs, OPAHs and NPAHs are partly from continental pollution (Fig. 4a). The abundance of these air pollutants in continental pollution, including 11-OBaFLN, has been shown in many studies (Bamford and Baker, 2003; Albinet et al., 2007; 2008; Wei et al., 2015; Tomaz et al., 2016; Drotikova et al., 2020; Lammel et al., 2020; Nežiková et al., 2021). The missing contribution of continental pollution to the concentration of 11-OBaFLN might be because of its comparably low atmospheric half-life due to degradation by OH (Table S2, US EPA, 2019). Continental pollution was highly abundant in the Mediterranean Sea (Fig. 4b), where we found the highest concentrations of the $\mathrm{OH}$ radical of the entire AQABA campaign. 1,4- $\mathrm{O}_{2} \mathrm{NAP}$ has a comparably high contribution of approx. $50 \%$ by this factor. As explained in Sect. 3.2.3, this might be explained by high relative concentrations at the source, high atmospheric lifetime and secondary formation during the transport of the air to the sampler. In contrast, 1,4- $\mathrm{O}_{2} \mathrm{NAP}$ seems to be significantly less abundant in pollution from the combustion of residual oil (Fig. 4a) and marine diesel (Table S17). However, more research is needed to evaluate this aspect in more detail. All PACs are abundant in desert dust, except for BAP and 2-NPYR. The presence of PAHs and PAH derivatives, especially 1-NPYR and 1,4- $\mathrm{O}_{2} \mathrm{NAP}$ in the factor desert dust (Fig. 4a) may indicate co-emissions of dust and PACs in the region (e.g. close to onshore industries). 

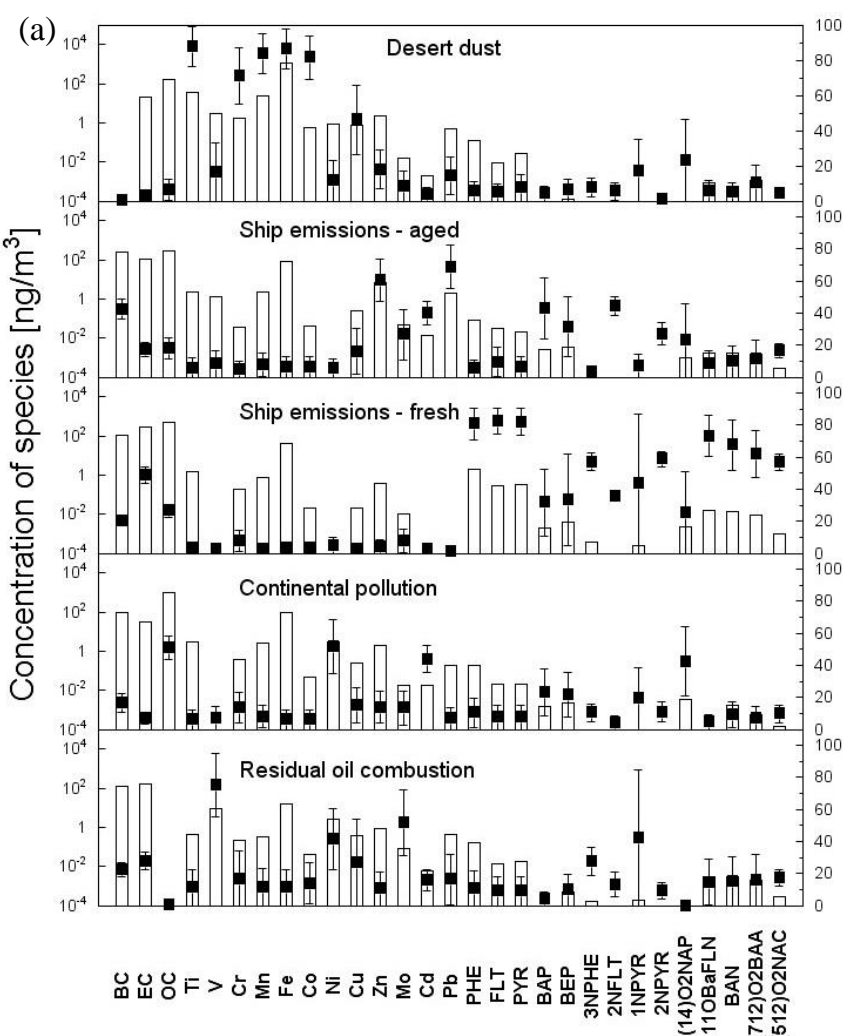

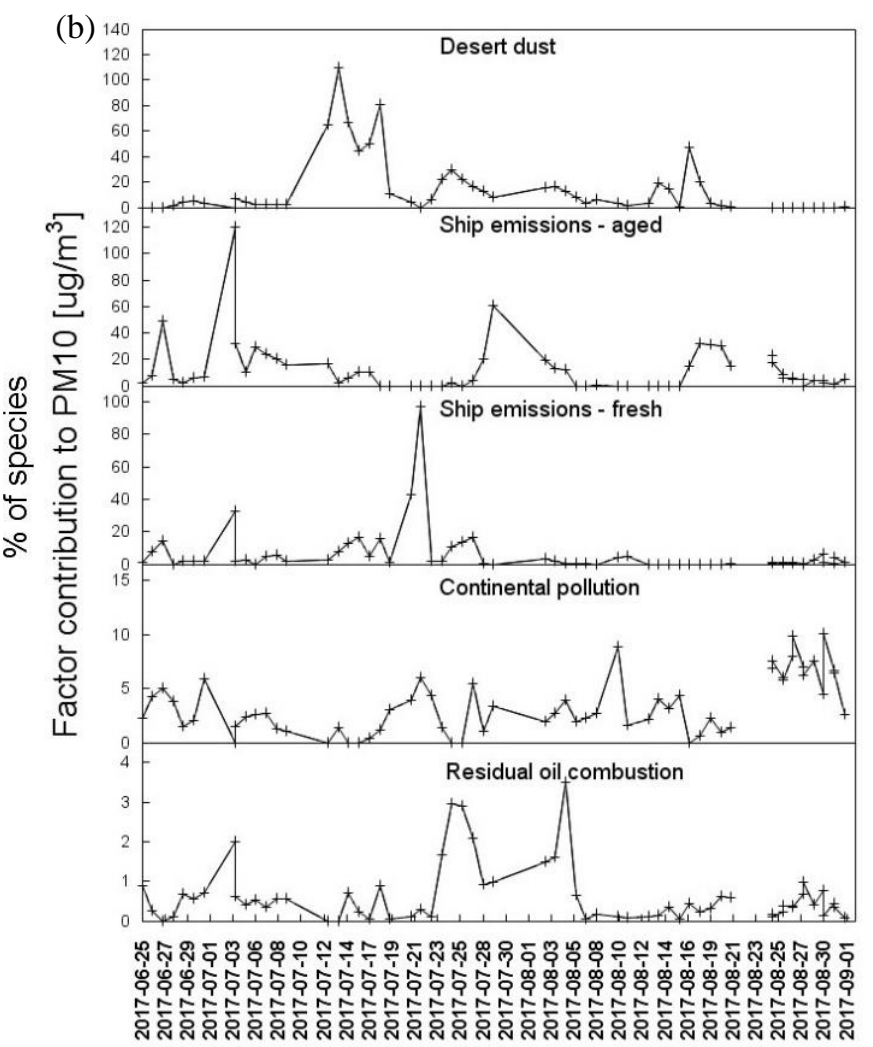

Figure 4: PMF group 2: (a) Factor profiles (Bars: Concentration of the species, black squares: Percentage of the species explained, box: Displacement (DISP) average, whiskers: DISP max and DISP min) and (b) time series of factor contributions to sample composition.

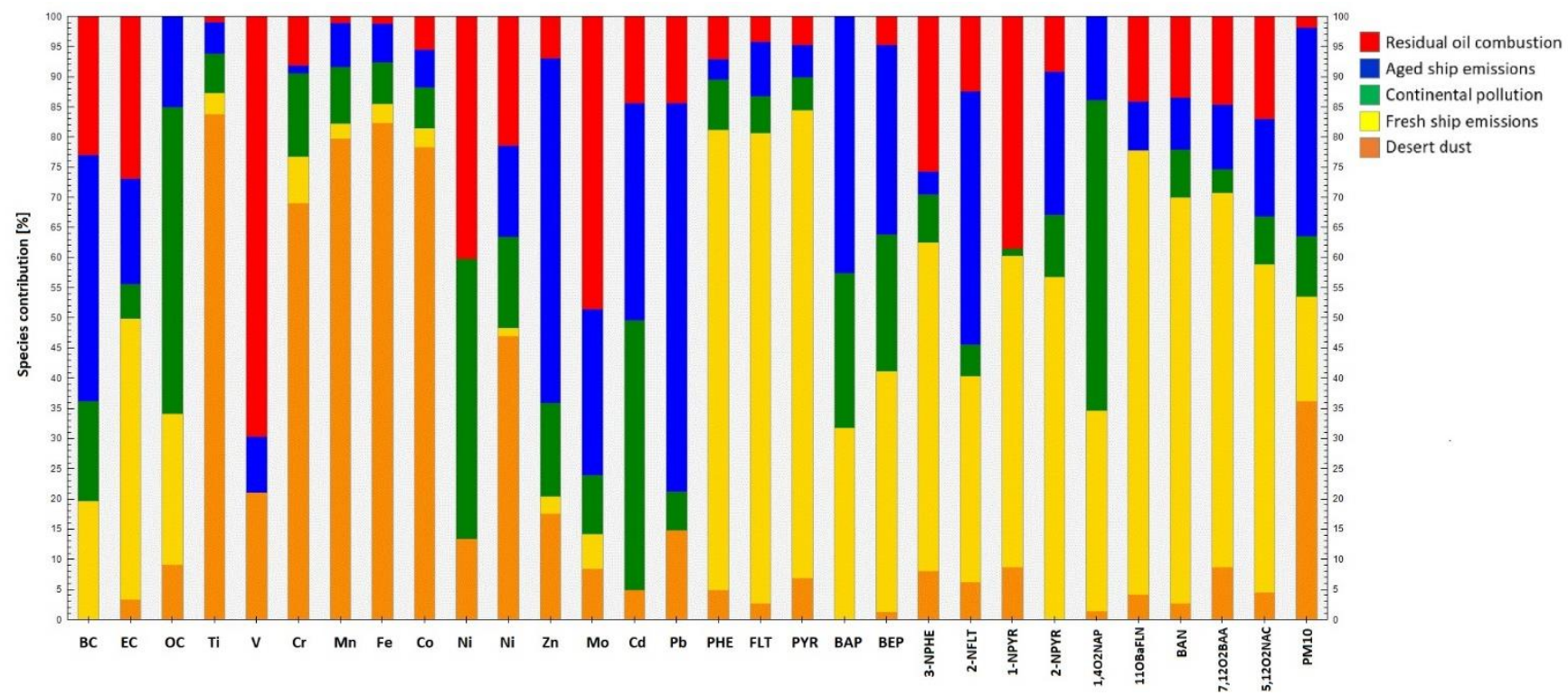

Figure 5: Relative contribution of the five factors resolved by PMF to the concentration of each substance in PMF group 2. 


\subsubsection{Source attribution by PAHs and alkylated PAHs}

The ratio of the particulate concentration of $\mathrm{BAP}$ to $\mathrm{BAP}+\mathrm{BEP}$ is often used as a marker for the ageing of atmospheric particles since photodegradation of BAP is faster than of BEP (Tobiszewski and Namieśnik, 2012). A concentration ratio $\mathrm{BAP} /(\mathrm{BAP}+\mathrm{BEP})$ of less than 0.5 indicates photochemically aged aerosols. The ratio was $<0.5$ in all regions and $\approx 0.5$ in the

540 Arabian Sea (see Fig. S5). The somewhat elevated ratio in the Arabian Sea might be caused by local ship plumes (for number of encounters see Table S18; identification based on Celik et al. (2020)) and other offshore emissions, which contributed to the mostly long-range transported and aged air pollution in the region. This is also supported by Bourtsoukidis et al. (2019) studying non-methane hydrocarbons during the AQABA campaign.

The relatively low ratios in all other regions might be explained by the low amount of primary sources of air pollutants on

545 sea except for ship traffic and some emissions from the offshore oil and gas industry. Thus, the pollution from urban and industrial areas, which are located mostly on the coast, is already slightly aged when reaching the sampler on the ship depending on the proximity to the emission sources. This could also be the explanation why the second-highest regional average values were found in the southern and the northern Red Sea receiving the emissions from the nearby coast as well as from the intense ship traffic in the region. The lowest regional average BAP/(BAP+BEP) values were detected in the Gulf of Oman and the Arabian Gulf. Air mass histories of sample D33 showed that a significant amount of aerosols came from less populated areas of Iran with a low amount of primary emissions (Fig. S3f, Wang et al., 2020). The results in the Mediterranean Sea can be divided into the first leg with a lower BAP/(BAP+BEP) ratio due to the prevalent westerly winds bringing aged air from Africa and from the sea and the second leg with higher ratios due to pollution from close European coastal areas and islands. The samples D58 and D49-52, close to Sicily and the Greek islands, respectively, showed the 555 highest $\mathrm{BAP} /(\mathrm{BAP}+\mathrm{BEP})$ ratios.

The ratio of $\Sigma$ MPHE/PHE $<1$ indicates pyrogenic origin of PAHs for most days in the Red Sea, while a ratio of MPHE/PHE $>1$ indicates petrogenic origin, i.e. from unburned fuel (Gogou et al., 1996), which occurred during the period from the 8-9 July 2017 in the northern Red Sea. Findings by Bourtsoukidis et al. (2020) could tentatively provide an explanation for the high ratio of $\Sigma$ MPHE/PHE observed, namely degassing from the Red Sea Deep water.

560 The ratio of the sum of the four MPHE homologues to PHE ( MPHE/PHE) and the ratio 1,7-M2PHE /(1,7-M2PHE + 2,6$\mathrm{M} 2 \mathrm{PHE})$ are given in Table S14. The distribution patterns and the concentration ratio 1,7- $\mathrm{M}_{2} \mathrm{PHE} /\left(1,7-\mathrm{M}_{2} \mathrm{PHE}+2\right.$,6$\mathrm{M}_{2} \mathrm{PHE}$ ) may be interpreted by considering the emission sources of these compounds. Bläsing et al. (2016) characterised and compared patterns of alkylated PAHs in gaseous and particulate emissions from road traffic (diesel), domestic heating, inland navigation vessels (INVs) and ocean-going vessels (OGVs). The ratio of 1,7-- $\mathrm{M}_{2} \mathrm{PHE} /\left(1,7-\mathrm{M}_{2} \mathrm{PHE}+2,6-\mathrm{M}_{2} \mathrm{PHE}\right.$ ) was

565 used to distinguish the above-mentioned emissions. Thus, the ratio of $1,7-\mathrm{M}_{2} \mathrm{PHE} /\left(1,7-\mathrm{M}_{2} \mathrm{PHE}+2,6-\mathrm{M}_{2} \mathrm{PHE}\right)$ for INVs $(0.37-0.62)$ is comparable with that from road traffic and domestic heating. In comparison, $1,7-\mathrm{M}_{2} \mathrm{PHE} /\left(1,7-\mathrm{M}_{2} \mathrm{PHE}+2,6-\right.$ $\mathrm{M}_{2} \mathrm{PHE}$ ) for marine oil combustion (as used for OGVs) was 0.68 (Budzinski et al., 1995). In the present study, the calculated average ratios were 0.63 (first leg) and 0.66 (second leg) for the Mediterranean, 0.64 and 0.62 for the Red Sea, 0.66 and 0.71 
for the Oman Gulf, 0.73 and 0.67 for the Arabian Gulf, respectively, and 0.61 (second leg) for the Arabian Sea. The calculated values for 1,7- $\mathrm{M}_{2} \mathrm{PHE} /\left(1,7-\mathrm{M}_{2} \mathrm{PHE}+2,6-\mathrm{M}_{2} \mathrm{PHE}\right)$ in the present study are within the range, 0.60-0.70, proposed by Bläsing et al. (2016) as an indicator for the emissions of OGVs.

\subsubsection{Source attribution by NPAHs and OPAHs}

Similar to the ratio of BAP/(BAP+BEP), the ratio of 2-NFLT/1-NPYR can indicate the photochemical age of aerosols. A ratio $<5$ shows the predominance of combustion sources, while a higher ratio indicates photochemically aged aerosols (Ciccioli et al., 1996). As illustrated in Fig. 6a, the highest regional average ratio of 2-NFLT/1-NPYR but also with the highest absolute and relative standard deviation was found over the Mediterranean Sea, followed by the southern and the northern Red Sea. However, the ratio was in only two samples (D1 and D58, collected over the Mediterranean Sea) higher than 5. In contrast, the ratio of BAP to BEP suggests aged aerosols in several samples as explained in Sect. 3.2.2.

The reason for the low incidence of high ratios could be that the concentrations of atmospheric oxidants $\mathrm{OH}$ and $\mathrm{NO}_{3}$ radicals as well as $\mathrm{NO}_{2}$ in some sea regions during the campaign were low (Bourtsoukidis et al., 2019; Tadic et al., 2020; Friedrich et al., 2021). The difference might be caused by different oxidants being responsible for degradation of BAP and formation of 2-NFLT. BAP, which is predominantly in the particulate phase, is mainly degraded by heterogeneous reaction with ozone (Shiraiwa et al., 2009), while 2-NFLT is mainly formed by homogeneous reaction of FLT with $\mathrm{OH}$ or $\mathrm{NO}_{3}$ (Atkinson and Arey, 1994; Reisen and Arey, 2005) and subsequent reaction with $\mathrm{NO}_{2}$. Ozone concentrations varied between 20 ppbv (in the Arabian Sea) and 150 ppbv (in the Arabian Gulf), while the variation of $\mathrm{NO}_{\mathrm{x}}$ was higher (from 50 pptv in Arabian Sea to more than 10 ppbv in the northern Red Sea and the Arabian Gulf) (Tadic et al., 2020; Friedrich et al., 2021). The highest $\mathrm{NO}_{\mathrm{x}}$ mixing ratios were found in the Northern Red Sea and the Gulf region, especially close to the Suez Canal, Kuwait and Fujairah (Tadic et al., 2020; Friedrich et al., 2021). $\mathrm{NO}_{2}$ concentrations are generally significantly smaller in the marine environment than on land, as shown by satellite data (Roşu et al., 2019) due to the short lifetime (Schaub et al., 2007; Shah et al., 2020) and missing sources for $\mathrm{NO}_{x}$ on sea except for ship traffic and the offshore oil and gas industry. Friedrich et al. (2021) calculated $\mathrm{NO}_{2}$ lifetimes of less than 6h during the AQABA campaign, which means that land-based $\mathrm{NO}_{\mathrm{x}}$ emissions will be degraded before reaching the sampler for several samples, especially in parts of the Mediterranean Sea. Missing primary sources and high degradation due to high $\mathrm{OH}$ radical concentrations explain the low $\mathrm{NO}_{\mathrm{x}}$ mixing ratios over the Mediterranean Sea (Friedrich et al., 2021). However, $\mathrm{NO}_{2}$ is crucial for the formation of 2-NFLT competing with $\mathrm{O}_{2}$ to either form NPAHs or OPAHs, respectively (Kamens et al., 1994; Finlayson-Pitts and Pitts, 1999; Atkinson and Arey, 2007).

The average 2-NFLT/1-NPYR ratio in air sampled over the Mediterranean Sea was significantly higher ( $\mathrm{p}<0.05$, Student's ttest) than in the air from Arabian Sea and the Gulf of Oman, respectively. Similarly, the ratio over the northern Red Sea was significantly higher $(\mathrm{p}<0.05$, Student's t-test) than over both Gulf regions. In polluted air near the coast (e.g. as found in the

600 Red Sea and at the beginning and the end of the campaign in the Mediterranean Sea) and in plumes (in samples D1, D30, D48 and D58), the 2-NFLT/1-NPYR ratio was high. These samples explain the high average 2-NFLT/1-NPYR ratio in the 
Mediterranean Sea and the northern Red Sea. The ratio can rise during transport of the pollutants. However, the formation of 2-NFLT slows down or stops probably due to low concentrations of the parent-PAH (FLT), the atmospheric oxidants OH and $\mathrm{NO}_{3}$ or $\mathrm{NO}_{2}$ since formation of 2-NFLT depends on these reactants (Wilson et al., 2020). This was also shown by Lammel et al. (2017), who found much larger yields of 2-NFLT and 2-NPYR in the marine background with urban influence compared to the marine background without significant pollution sources.

In contrast to the regions with polluted air, a low ratio was observed in air over the Arabian Sea and in the parts of the Mediterranean Sea far from the coast. Due to these samples with low 2-NFLT/1-NPYR ratios in the Mediterranean Sea, the standard deviation of the regional average ratio is the highest among all sea regions. The average ratio in the Arabian Sea was only 0.36 (taking LOQ/2 values of 1-NPYR into account). This points to primary sources (as indicated in Sect. 3.3.2) and/or very low $\mathrm{NO}_{2}$ concentrations in the sampled air masses, as shown by Friedrich et al. (2021). When secondary formation far away from sources is not significant anymore, the differences in characteristic time for chemical (which is primarily photolysis) and physical sinks (which is primarily particle deposition) determine the ratio 2-NFLT/1-NPYR. One influencing factor might be the difference in deposition velocity of the two compounds due to the different particulate

615 fractions, which is lower for 2-NFLT (not shown, gas-particle partitioning is studied in a separate paper). A lower particulate mass fraction of 2-NFLT might lead to a slower deposition of this compound compared to 1-NPYR, which would lead to higher ratios. In contrast, a lower ratio would be the result of the faster degradation of 2-NFLT by OH and ozone compared to the degradation of 1-NPYR (Table S2, USEPA, 2019). In contrast, 1-NPYR is probably more prone to photodegradation, although the photodegradation rates strongly depend on the aerosol composition (Feilberg and Nielsen, 2000). The removal and degradation rates are reported to be approximately similar (Kamens et al., 1994; Fan et al., 1996; Feilberg and Nielsen, 2000; Albinet et al., 2008). However, this may not be the case in this study due to exceptionally low particulate mass fractions of the PACs due to the high temperature and the low EC and OC concentrations in the aerosols (Table S15). If degradation of 2-NFLT plays a larger role in the investigated regions, the ratio of 2-NFLT/1-NPYR would decrease with time, when there is no formation of 2-NFLT. This might be another explanation for the low 2-NFLT/1-NPYR ratios in some sea regions. However, more research is needed on the exact kinetics influencing the ratio, especially the photolysis rate coefficients. At continental sites, the ratio of 2-NFLT/1-NPYR mostly increases with distance to the emission source due to the significant formation of 2-NFLT (Ciccioli et al., 1996; Nežiková et al., 2021). 


\section{(a)}

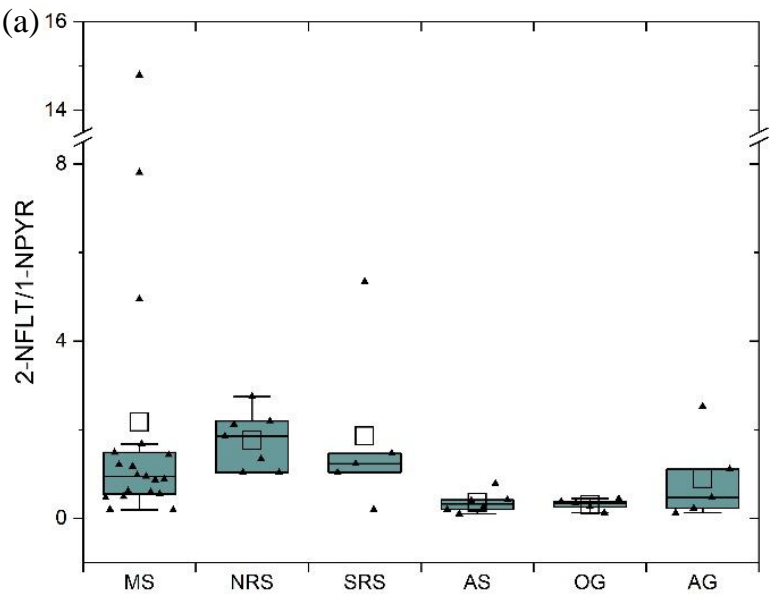

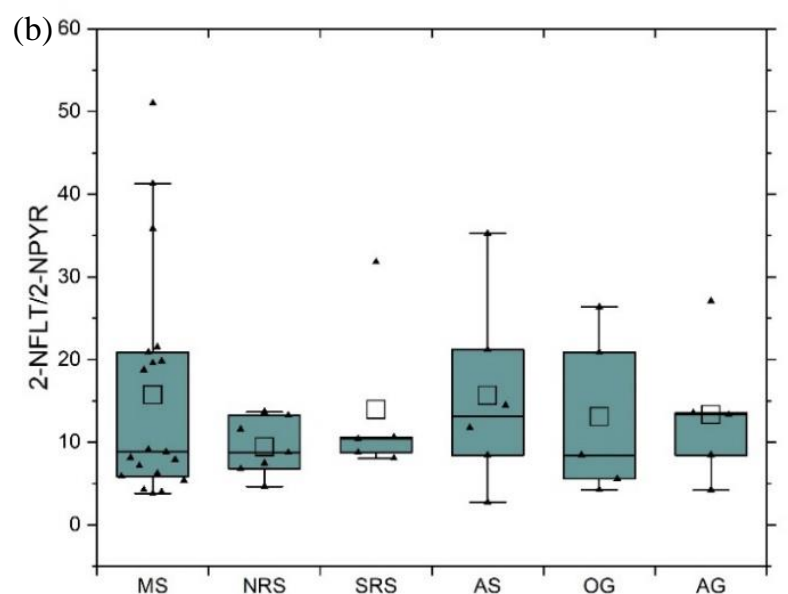

Figure 6: Box-Whisker plot of the ratios (a) 2-NFLT/1-NPYR and (b)2-NFLT/2-NPYR across sea regions (MS: Mediterranean Sea; NRS: northern Red Sea; SRS: southern Red Sea; AS: Arabian Sea; OG: Gulf of Oman; AG: Arabian Gulf; Empty square: mean value; Filled, grey triangles: Measurement points; Box with additional borders: interquartile range (IQR) bound by the $75^{\text {th }}$ and $25^{\text {th }}$ percentile and range of $1.5 \mathrm{IQR}$; Horizontal line: Median).

Since 2-NPYR is almost entirely formed by the reaction of PYR with OH radicals during daytime, while 2-NFLT can be formed by daytime reaction with $\mathrm{OH}$ as well as by nighttime reaction with $\mathrm{NO}_{3}$, the ratio of 2-NFLT/2-NPYR can reveal the predominant formation pathway of NPAHs (Feilberg et al., 2001; Bamford and Baker, 2003). The main formation pathway during the campaign was the $\mathrm{OH}$ radical initiated formation, since the average concentration ratio of 2-NFLT/2-NPYR was $15.1 \pm 11.6$. This is close to a ratio of 5-10, suggesting the predominant formation of NPAHs by OH radicals and far from a ratio of $>100$, which would indicate reactions mainly involving the $\mathrm{NO}_{3}$ radical. This result is similar to the findings by Tang et al. (2014) at a remote site on a Japanese peninsula. Lammel et al. (2017) determined even lower 2-NFLT/2-NPYR ratios in the eastern Mediterranean Sea, also pointing to a predominant NPAH formation by hydroxyl radicals.

As illustrated in Fig. 6b, the lowest average ratio (9.5) was found in the northern Red Sea, while the ratio of 15.8 (first leg: 22.3; second leg: 13.4) in the Mediterranean Sea was the highest regional average value. The high value in the Mediterranean Sea during the first leg was due to two exceptionally high values in samples D1 and D5. The formation of these NPAHs will be largely determined by the accumulated nighttime $\mathrm{NO}_{2}$ and the actinic flux during the day, the air mass had been exposed to prior sampling. For example, samples D52 and D56 had relatively high ratios since the aerosols have picked up $\mathrm{NO}_{\mathrm{x}}$ emissions from the urban areas of Athens and Istanbul (D52) or Rome and Naples (D56) in a previous night, which can be converted to the $\mathrm{NO}_{3}$ radical by the reaction with ozone. Whereas the samples D50 and D54, which had not picked up $\mathrm{NO}_{x}$ emissions from particular source areas within $\approx 48 \mathrm{~h}$, did not show a high 2-NFLT/2-NPYR ratio.

\subsubsection{PAHs and derivatives in photochemically aged pollution}

650 A high ratio of the secondarily formed PAH derivatives 2-NPYR and 2-NFLT (Arey et al., 1986; Bamford and Baker, 2003; Reisen and Arey, 2005) to their parent PAHs indicates long-range transported aerosols with a significant concentration of the 
atmospheric oxidants $\mathrm{OH}$ and $\mathrm{NO}_{3}$ as well as $\mathrm{NO}_{2}$. Similar to the ratio of 2-NFLT/1-NPYR, the highest ratios were observed in air over the Mediterranean Sea (especially during the first leg in aged aerosols). We determined the highest ratios in sample D1 at the beginning of the campaign close to Sardinia and Sicily. Another high ratio was found in sample D30 in the Arabian Gulf. As already revealed by Wang et al. (2020), photochemically aged air reached the ship from the first night of the first leg in the Arabian Gulf (28 July 2017 16:00 UTC) until the 30 July 2017 at 00:00 UTC (see air mass histories in Fig. 7a), as evidenced by high mixing ratios of some carbonyl compounds such as acetone. After that, the air was dominated by fresh emissions, while approaching Kuwait. According to the distribution of residence times of air masses, the air arrived from northwest with influence of several oil fields and refineries in that region (Fig. 7b and S3f; Bourtsoukidis et al., 2019; Pfannerstill et al., 2019; Wang et al., 2020). Thus, the samples from the first leg in the Arabian Gulf were affected by fresh emissions as well as photochemically aged air. Apart from 2-NFLT/FLT and 2-NPYR/PYR, several other PAH derivatives

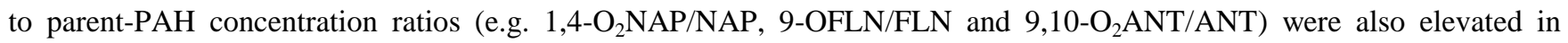
sample D30, showing the high contribution of photochemically aged air. In addition, the results indicate that these PAH derivatives are secondarily formed or significantly slower degraded and deposited than their parent PAH.

665 Another sample with a high ratio of secondarily formed NPAHs is sample D48 in the northern Red Sea nearby the Suez Canal. Similar to the first night in the Arabian Gulf, Wang et al. (2020) determined a high OH exposure during the first night in the Gulf of Suez (from the 22-23 August 2017) accompanied by a high mixing ratio of acetone. The finding that aerosols sampled between the 22 and 23 August 2017 (D48) were atmospherically aged, is supported the high PAH derivative/parent PAH ratios (e.g. of 2-NFLT/FLT, 2-NPYR/PYR, 7-NBAA/BAA, 1,4-O 2 NAP/NAP and 9,10- ${ }_{2}$ ANT/ANT). The enhanced formation of NPAHs and OPAHs from atmospheric reactions in this area commensurate with high concentrations of $\mathrm{NO}_{2}$, and comparably high production rates of the $\mathrm{NO}_{3}$ radical in this sea region, as reported by Eger et al. (2019). In addition, sample D48 is also affected by primary emissions, e.g., from oil refineries and shipping emissions (Bourtsoukidis et al., 2019). This is supported by the PMF, suggesting aged shipping emissions as well as continental pollution as the major sources.

675 Generally, low and high NPAH/PAH and OPAH/PAH ratios coincided with $\mathrm{NO}_{\mathrm{x}}$ and radical availabilities. The highest concentrations of PAHs (D54) as well as of NPAHs and OPAHs (D58) were found in air masses carrying continental pollution, sampled in the Mediterranean Sea (from south-east Europe, covering major urban areas including Thessaloniki and Istanbul as well as from Sicily, Corsica, Sardinia and parts of continental Italy, respectively; Figs. 7c and d). While night-time sample D54 corresponded to low $\mathrm{NO}_{\mathrm{x}}$ and low $\mathrm{OH}$ and $\mathrm{NO}_{3}$ radical concentrations, $24 \mathrm{~h}$ sample D58 corresponded to high $\mathrm{OH}$ and $\mathrm{NO}_{\mathrm{x}}$ concentrations (Tadic et al., 2020; Friedrich et al., 2021). 
(a)

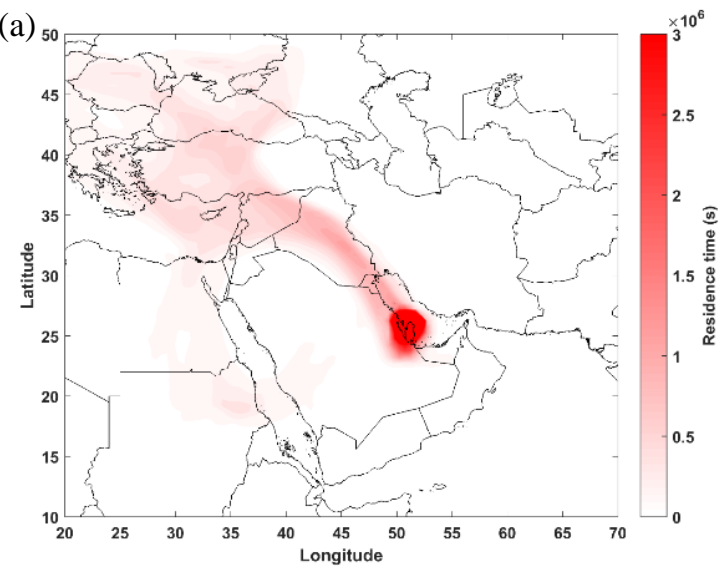

(c) $)_{55}$

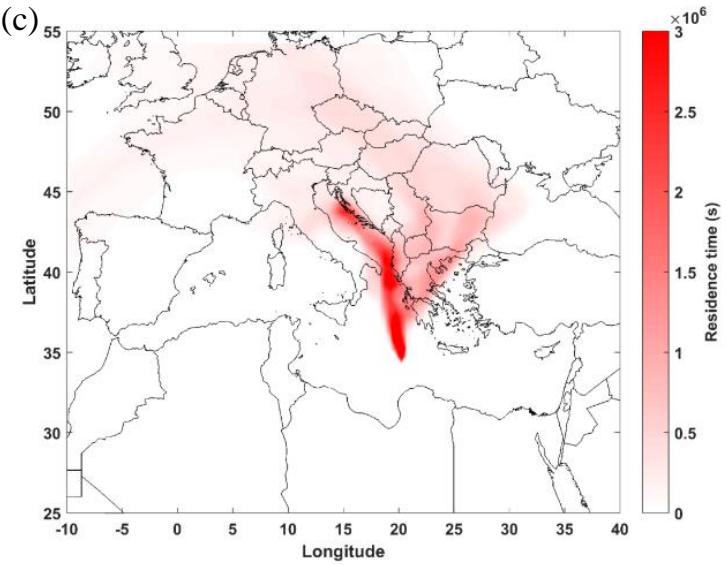

(b)

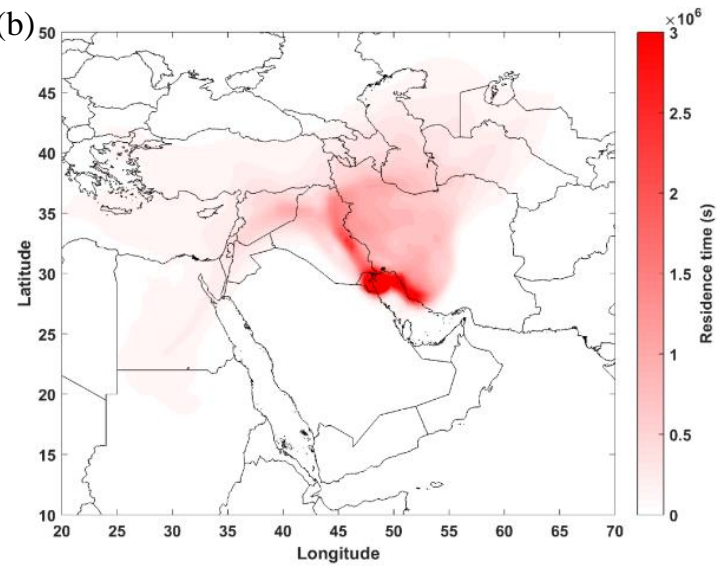

$(\mathrm{d})_{55}$

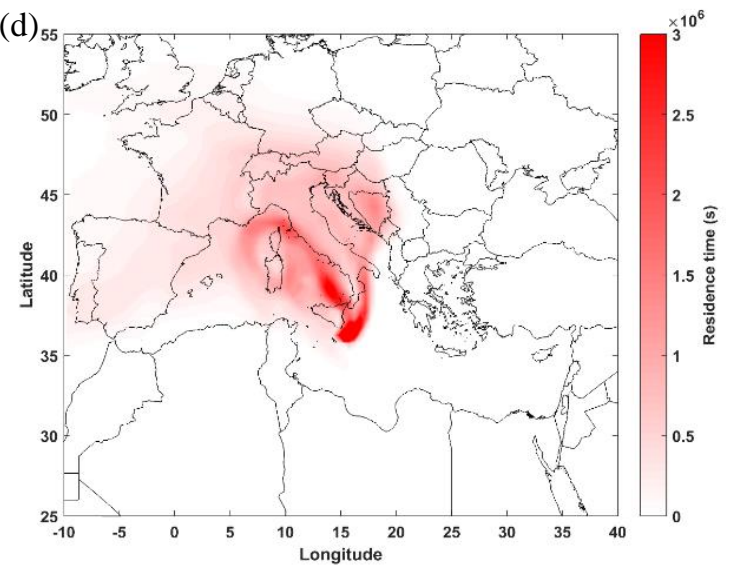

Figure 7: Distribution of residence times of air masses received in the Arabian Gulf: (a) D30 (29-30 July 2017), (b) D31 (3-4 August 2017) and the Mediterranean Sea: (c) D54-55 (27-28 August 2017), (d) D58 (29-30 August 2017) using FLEXPART Lagrangian particle dispersion model samples.

\subsubsection{Significance of OPAHs and NPAHs photochemical sources}

We found a significant positive correlation of 7,12- $\mathrm{O}_{2}$ BAA with the ratio of 2-NFLT/1-NPYR $(\mathrm{r}=0.83, \mathrm{p}<0.05)$, which is typically used as an indicator for the contribution of PAH derivatives formed from oxidative reactions. Several laboratory studies have shown that 7,12- $\mathrm{O}_{2} \mathrm{BAA}$ is formed from the heterogeneous reaction of BAA with $\mathrm{O}_{3}$ alone and also with the combination of $\mathrm{O}_{3}$ and $\mathrm{NO}_{2}$ (Gao et al., 2009; Ringuet et al., 2012a, b). The formation of 7,12- $\mathrm{O}_{2} \mathrm{BAA}$ from the photochemical reaction of BAA has also been reported (Jang and McDow, 1997; Shen et al., 2007). In our current study, the quinone weakly, not significantly correlated with ozone $(\mathrm{r}=0.25, \mathrm{p}=0.11)$, the $\mathrm{OH}$ concentration $(\mathrm{r}=0.29, \mathrm{p}=0.11)$ and the actinic flux $(r=0.23, p=0.14)$. The weak correlation of the ratio of 7,12- $\mathrm{O}_{2} \mathrm{BAA}$ and the parent-PAH BAA with the actinic flux $(r=0.28, p=0.07)$ was the strongest correlation among all PAH derivative/PAH ratios. However, the secondary formation of 7,12- $\mathrm{O}_{2} \mathrm{BAA}$ is expected to be only a part of the total burden of this quinone. We also found correlations with primary 
pollutants, suggesting primary emissions. Similarly, Lin et al. (2015) reported that around $30 \%$ of $7,12-\mathrm{O}_{2} \mathrm{BAA}$ in atmospheric PM sampled in Beijing was secondarily formed.

Lin and colleagues (2015) also found significant secondary formation of 3-NPHE and 7-NBAA. Tomaz et al. (2017) even suggested 3-NPHE to be used as a marker for secondary formation from PHE. However, 3-NPHE is not or only to trace amounts formed by homogeneous reactions with $\mathrm{OH}$ or $\mathrm{NO}_{3}$ (Atkinson and Arey, 1994; Helmig and Harger, 1994; Lee and Lane, 2010). Though, Ringuet et al. (2012a) reported the formation of 3-NPHE and 7-NBAA by heterogeneous formation with atmospheric oxidants. Liu et al. (2019) found a correlation between 2-NFLT and 7-NBAA. We observed a significant correlation of the ratio 2-NFLT/1-NPYR with 3-NPHE $(r=0.44, \mathrm{p}<0.05)$ but not with 7-NBAA $(\mathrm{r}=0.01, \mathrm{p}=0.91)$. 7-NBAA was positively correlated with the concentration of the $\mathrm{NO}_{3}$ radical and $\mathrm{NO}_{2}(\mathrm{r}=0.60, \mathrm{p}<0.05$ and $\mathrm{r}=0.67, \mathrm{p}<0.05$, respectively), but not with the $\mathrm{OH}$ radical. 3-NPHE showed a weak correlation with $\mathrm{NO}_{2}(\mathrm{r}=0.28, \mathrm{p}=0.1)$ and the actinic flux $(0.25, \mathrm{p}=0.11)$. Based on the high emission factors of 3-NPHE and 7-NBAA in diesel combustion (Heeb et al., 2008; Zhao et al., 2019), we expect primary pollution as the major source of these compounds and only a minor contribution from secondary formation. This is supported by Zhuo et al. (2017), who report a contribution from secondary formation of only 3 $10 \%$ to the total concentration of 3-NPHE in the city Nanjing in eastern China.

710 The secondary formation of 2-NNAP and 1,4- $\mathrm{O}_{2}$ NAP has already been determined earlier (Atkinson and Arey, 1994; Kautzman et al., 2010; Keyte et al., 2013) and was suggested by source attribution (Zhuo et al., 2017). 2-NNAP correlated with the ratio 2-NFLT/1-NPYR $(r=0.46, p<0.01)$, while 1,4- ${ }_{2}$ NAP only showed a weak correlation with the ratio $(r=0.29$, $\mathrm{p}=0.06)$. 2-NNAP correlated with $\mathrm{NO}_{2}(\mathrm{r}=0.38, \mathrm{p}<0.05)$. 1,4- $\mathrm{O}_{2} \mathrm{NAP}$ showed a weak positive correlation with $\mathrm{O}_{3}(\mathrm{r}=0.22$, $\mathrm{p}=0.14$ ). Both compounds are highly abundant in primary emissions, as already mentioned. Thus, 2-NNAP and 1,4- $\mathrm{O}_{2} \mathrm{NAP}$

715 might have contributions from primary and secondary formation depending on the region.

From the literature, it is known that 9-OFLN and 9,10- $\mathrm{O}_{2}$ ANT can be formed in the atmosphere, mainly through the reaction of their parent PAH with $\mathrm{O}_{3}$ and $\mathrm{OH}$ (Helmig and Harger, 1994; Perraudin et al., 2007; Wang et al., 2007; Keyte et al., 2013). In addition, source analysis of polluted air in the Chinese megacity Nanjing showed a significant contribution of secondarily formed 9-OFLN and 9,10- $\mathrm{O}_{2}$ ANT to the total concentration (Zhuo et al., 2017). In our dataset, we could find a positive correlation of these two OPAHs (significant only for 9-OFLN) with the concentration of $\mathrm{O}_{3}(\mathrm{r}=0.42, \mathrm{p}<0.01$ and $\mathrm{r}=0.27, \mathrm{p}=0.08$, respectively). Furthermore, 9-OFLN showed a significant positive correlation with the ratio 2-NFLT/1NPYR $(r=0.33$, $\mathrm{p}<0.05)$, while 9,10- $\mathrm{O}_{2}$ ANT only showed a weak correlation $(\mathrm{r}=0.22, \mathrm{p}=0.15)$. Based on the results from the PMF and other literature, we expect primary emissions as the major source of both OPAHs with a small contribution of secondary formation to the concentration of 9-OFLN and 9,10-O 2 ANT.

1-(CHO)NAP was already reported to be secondarily formed by ozonolysis from ACY, 1-methylnaphthalene and possibly other precursors within hours (Dang et al., 2015). It is significantly correlating with the ratio of 2-NFLT/1-NPYR (r=0.42, $\mathrm{p}<0.05)$ and shows a very weak, not significant correlation with ozone $(\mathrm{r}=0.11, \mathrm{p}=0.47) .5,12-\mathrm{O}_{2} \mathrm{NAC}$ showed a very weak correlation with ozone $(\mathrm{r}=0.18, \mathrm{p}=0.25)$. However, we are not aware of any study showing secondary formation of this quinone. In contrast, 11-OBbFLN can be formed by the reaction of the parent PAH with ozone (Ringuet et al., 2012a). 
However, we did not find any correlation. Thus, there is no clear indication for significant secondary formation of 11OBaFLN, 11-BbOFLN and BAN, based on the correlation analysis.

In conclusion, our observations indicate photochemical sources to significantly have influenced 2-NFLT, 2-NPYR, 1,4$\mathrm{O}_{2} \mathrm{NAP}$ and 7,12- $\mathrm{O}_{2}$ BAA levels, while this was not the case for 1-NPYR, 11-OBaFLN, 11-BbOFLN and BAN. Indications for secondary formation but possibly only minor were found for 2-NNAP, 3-NPHE, 7-NBAA, 9-OFLN, 1-(CHO)NAP and

\subsection{Mass size distributions}

The highest concentrations of PAHs, OPAHs and NPAHs are found in the sub-micrometre fraction of particulate matter, $\mathrm{PM}_{1}$. Fig. 8 shows the campaign average mass size distributions of the PAHs and PAH derivatives. The mass size distributions of PAHs, NPAHs and OPAHs are mainly unimodal given the coarse size resolution of the impactor with 6 size ranges within $\mathrm{PM}_{10}$. The maximum was found in particles with an aerodynamic diameter $<0.49 \mu \mathrm{m}$. For the sum of PAHs, four samples showed an apparently unimodal distribution with a maximum at a particle diameter of $0.49-0.95 \mu \mathrm{m}$ in the accumulation mode instead of the lowest particle size. In addition, three samples (two in the Arabian Gulf and one in the Arabian Sea) showed a bimodal distribution with maxima in particles with an aerodynamic diameter $<0.49 \mu \mathrm{m}$ and of $0.95-$ $1.5 \mu \mathrm{m}$. For the sum of NPAHs, only one sample (in the Mediterranean Sea) showed an apparently unimodal distribution with a maximum in another aerodynamic particle diameter range than $<0.49 \mu \mathrm{m}(0.49-0.95 \mu \mathrm{m})$. Since we did not resolve the $<0.49 \mu \mathrm{m}$ size fraction, more modes in the sub-micrometre fraction, as found by di Filippo et al. (2010) cannot be excluded.

The ratio between the concentrations in particles $<0.49 \mu \mathrm{m}$ compared to the concentrations in coarse mode PM particles is greater for high-molecular-weight PACs compared to low-molecular-weight PACs and higher for PAH derivatives compared to the parent-PAHs. This can be explained by the lower vapour pressure of PAH derivatives and high-molecular-weight PAHs compared to the parent-PAHs and low-molecular-weight PAHs. Compounds with lower vapour pressure are less subject to redistribution across particles sizes during transport (Degrendele et al., 2014). The process of redistribution is more effective that the pollutants reach higher particle size fractions than the process of coagulation of particles to form larger particles, which would transfer low vapour pressure PACs to bigger particle size fractions. The dependency of the vapour pressure on the mass median diameter was only found for PAHs and was not significant. This can partly be explained by limited explanatory power of the mass median diameter in this study due to low concentrations of e.g. the 3-ring PAHs and some NPAHs, leading to no detectable amount in coarse mode particles. The NPAHs generally had a low concentration in our study and the low-molecular-weight PAHs were not abundant in PM since these substances are preferable in the gas phase. The campaign average mass median diameters of the target compounds are shown in the Supplement Table S19.

760 Since the process of redistribution depends on time, a shift of the mass median diameter to larger particles sizes is found for aged aerosols (see exemplary Fig. S6). For instance, Lammel et al. (2017) found two maxima for the 4-ring PAHs at a marine background site (same cascade impactor as the one used in this study). The second maximum was explained by aged 
https://doi.org/10.5194/acp-2022-32

Preprint. Discussion started: 18 January 2022

(c) Author(s) 2022. CC BY 4.0 License.

(c) (1)

aerosols at the marine site. The samples showing a maximum of the sum of PAHs at higher particle diameters in our study can also be attributed to aged aerosols (aged samples C6 and C7 in Arabian Gulf; C27, C28 in Mediterranean Sea without

765 close primary emission sources; C22 in very clean air over the Arabian Sea, C24 in southern Red Sea possibly because of Saharan dust).
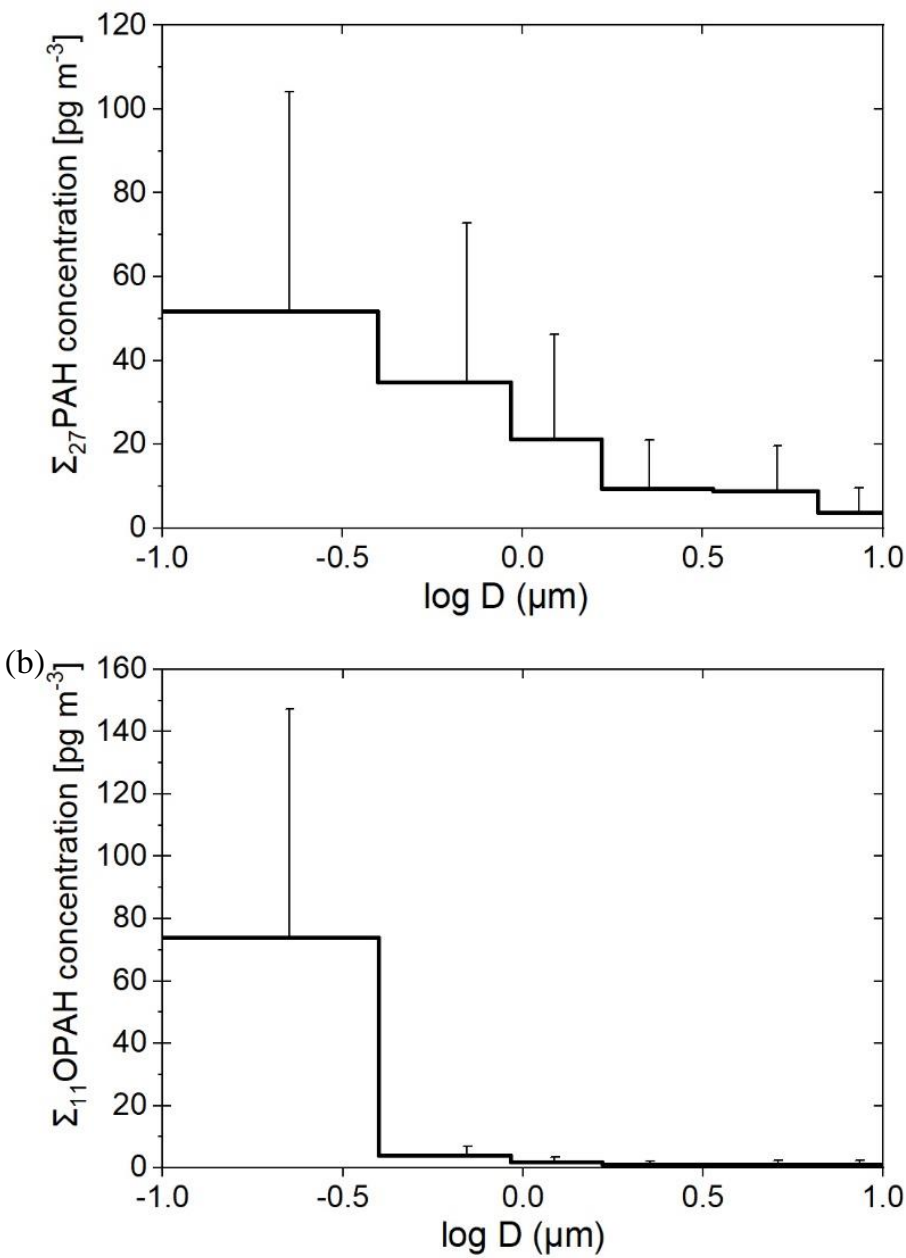

(c) 


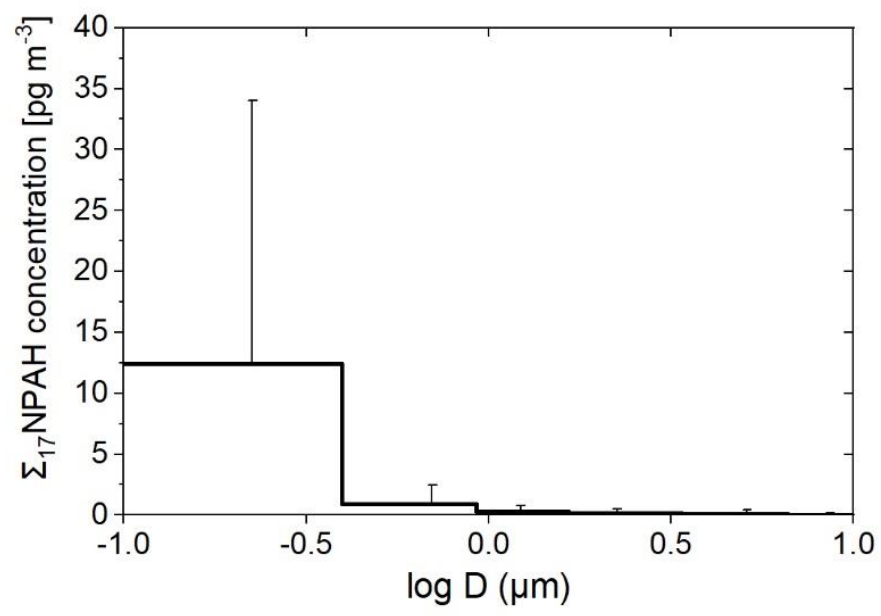

770 Figure 8: Campaign average mass size distributions of (a) $\sum_{27}$ PAHs, (b) $\sum_{11}$ OPAHs and (c) $\sum_{17}$ NPAHs during the campaign; including standard deviation as error bars.

\section{Conclusions}

For the first time, PAHs and their derivatives were measured in the marine environment around the entire Arabian Peninsula in a comprehensive ship campaign. The atmospheric average concentrations of $\sum_{27} \mathrm{PAHs}, \sum_{19} \mathrm{RPAHs}, \sum_{11} \mathrm{OPAHs}$ and

$775 \sum_{17} \mathrm{NPAHs}$ in the gas and particulate phase were $2.85 \pm 3.35 \mathrm{ng} \mathrm{m}^{-3}, 0.83 \pm 0.87 \mathrm{ng} \mathrm{m}^{-3}, 0.24 \pm 0.25 \mathrm{ng} \mathrm{m}^{-3}$ and $4.34 \pm 7.37$ $\mathrm{pg} \mathrm{m}^{-3}$, respectively. The lowest burden of all targeted pollutant classes was observed in the Arabian Sea with concentrations among the lowest ever reported, followed by the southern Red Sea. The highest average concentrations of the PAHs and the OPAHs were detected in the Mediterranean Sea, while the NPAHs were most abundant in the Arabian Gulf. It was observed that the regional differences in the composition patterns of the NPAHs and OPAHs were more pronounced than those of the PAHs and RPAHs. 1,4-O $\mathrm{O}_{2} \mathrm{NAP}, 9-\mathrm{OFLN}$ and 9,10- $\mathrm{O}_{2}$ ANT were the most abundant OPAHs. The NPAH composition pattern was dominated by a high contribution of 2-NNAP, followed by 1-NPYR, which was highly abundant in the Gulf region. Photochemical formation of 2-NFLT, 2-NPYR, 2-NNAP, 3-NPHE, 7-NBAA, 1,4-O NAP, 1-(CHO)NAP, 9-OFLN, 9,10$\mathrm{O}_{2}$ ANT and 7,12- $\mathrm{O}_{2}$ BAA was indicated, while for 1-NPYR, 11-OBaFLN, 11-OBbFLN and BAN secondary sources were not significant.

785 Source apportionment showed that the PAHs and their nitrated and oxygenated derivatives mainly originated from fresh and aged shipping emissions. All OPAHs and NPAHs except 2-NFLT, which were frequently detected during the campaign, showed elevated concentrations in fresh shipping emissions. 1-NPYR among the NPAHs and 11-OBaFLN and 1(CHO)NAP among the OPAHs showed the highest relative increase in their concentration. In contrast, 2-NFLT and 2-NPYR were highly abundant in aged shipping emissions due to secondary formation. 1-NPYR, 3-NPHE and several OPAHs had a significant contribution from residual oil combustion. PAH derivatives were clearly enriched in long-range transported plumes from polluted regions in Egypt, the Arabian Gulf, and southern and eastern Europe. Throughout the campaign, the 
highest concentrations of PAHs, OPAHs and NPAHs were found in the sub-micrometre fraction of particulate matter $\left(\mathrm{PM}_{1}\right)$. Due to redistribution, the mass median diameter was shifted to higher values in long-range transported aerosols.

Data availability. The data used in this study are archived and distributed through the KEEPER service of the Max Planck Digital Library (https://keeper.mpdl.mpg.de, last access: 12 December 2021) and have been available from August 2019 to all scientists agreeing to the AQABA protocol.

Supplement. The supplement related to this article is available online at:

Author contributions. MW evaluated the data and wrote the manuscript. GL supervised this study. MI and RP did the sampling. MK, MI and ES provided the data about alkylated PAHs and wrote this part. PPo performed the PMF and wrote the part. BN created the FLEXPART Lagrangian particle dispersion model results. JK provided the data about metals. PK and PPr performed the PAH, NPAH and OPAH sample preparation and analysis. IT created GPS plots and provided $\mathrm{NO}_{\mathrm{x}}$ and $\mathrm{O}_{3}$ data. NF, PE and $\mathrm{JNC}$ contributed measurements of $\mathrm{NO}_{2}, \mathrm{NO}_{\mathrm{X}}, \mathrm{NO}_{\mathrm{y}} \mathrm{O}_{3}$ and $\mathrm{SO}_{2}$. RR and $\mathrm{ST}$ provided $\mathrm{OH}$ radical data. JW was involved in the discussion about the sources. The stack filter and information about bypassing ships as well as $\mathrm{BC}$ and surface PAH concentrations were provided by FD and SC. HH took responsibility for the scientific coordination of the field campaign on board the research vessel. JL designed the AQABA campaign. GL designed this study, supported by ES and UP. All authors contributed to data interpretation and manuscript revision and approved the submitted version.

Competing interests. The authors declare that they have no conflict of interest.

Acknowledgements. We thank Hays Ships Ltd, Captain Pavel Kirzner and the Kommandor Iona's ship crew for the great support. We would like to thank Marcel Dorf and Claus Koeppel for the organization of the campaign, Hartwig Harder for

815 the management on board, and all other participants and supporters of the campaign. We thank Benedikt Steil for processing meteorological data and Jan Schuladen for the data about the actinic flux. We also thank Abdulaziz al Senafi (Kuwait Inst. of Scientific Research). In addition, we thank Ondrej Sanka for the assistance in the plotting of sampling stretches. This research was supported by the Max Planck Society and by the Czech Ministry of Education, Youth and Sports - Research Infrastructure RECETOX RI (No LM2018121 and CZ.02.1.01/0.0/0.0/16_013/0001761), the project CETOCOEN EXCELLENCE (No CZ.02.1.01/0.0/0.0/17_043/0009632) and the Czech Science Foundation (GACR \#20-07117S). This project was supported from the European Union's Horizon 2020 research and innovation programme under grant agreement No 857560. This publication reflects only the author's view and the European Commission is not responsible for any use that may be made of the information it contains.

825 Financial support. The article processing charges for this open-access publication were covered by the Max Planck Society. 
Review statement.

\section{References}

Abbas, I., Badran, G., Verdin, A., Ledoux, F., Roumie, M., and Courcot, D.: Polycyclic aromatic hydrocarbon derivatives in airborne particulate matter: sources, analysis and toxicity, Environ. Chem. Lett., 16, 439-475, https://doi.org/10.1007/s10311-0170697-0, 2018.

Albinet, A., Leoz-Garziandia, E., Budzinski, H., and Villenave, E.: Polycyclic aromatic hydrocarbons (PAHs), nitrated PAHs and oxygenated PAHs in ambient air of the Marseilles area (south of France): concentrations and sources, Sci. Total Environ., 384, 280-292, http://dx.doi.org/10.1016/j.scitotenv.2007.04.028, 2007.

Albinet, A., Leoz-Garziandia, E., Budzinski, H., Villenave, E., and Jaffrezo, J. L.: Nitrated and oxygenated derivatives of polycyclic aromatic hydrocarbons in the ambient air of two French alpine valleys. Part 1: concentrations, sources and gas/particle partitioning, Atmos. Environ., 42, 43-54. https://doi.org/10.1016/j.atmosenv.2007.10.009, 2008.

Alves, C. A., Vicente, A. M., Custódio, D., Cerqueira, M., Nunes, T., Pio, C., Lucarelli, F., Calzolai, G., Nava, S., Diapouli, E., Eleftheriadis, K., Querol, X., and Bandowe, B. A. M.: Polycyclic aromatic hydrocarbons and their derivatives (nitro-PAHs, oxygenated PAHs, and azaarenes) in $\mathrm{PM}_{2.5}$ from southern European cities, Sci. Total Environ., 595, 494-504, http://dx.doi.org/10.1016/j.scitotenv.2017.03.256, 2017.

Andersson, J. T. and Achten, C.: Time to say goodbye to the 16 EPA PAHs? Toward an up-to-date use of PACs for environmental purposes, Polycyclic Aromat. Compd., 35, 330-354, https://doi.org/10.1080/10406638.2014.991042, 2015.

845 Arey, J., Zielinska, B., Atkinson, R., Winer, A. M., Ramdahl, T., and Pitts, J. N.: The formation of nitro-PAH from gasphase reactions of fluoranthene and pyrene with the $\mathrm{OH}$ radical in the presence of $\mathrm{NO}_{\mathrm{x}}$, Atmos. Environ., 20, 23392345, https://doi.org/10.1016/0004-6981(86)90064-8, 1986.

Atkinson, R. and Arey, J.: Atmospheric chemistry of gas-phase polycyclic aromatic hydrocarbons: formation of atmospheric mutagens, Environ. Health Perspect., 102, 117-126, https://doi.org/10.1289/ehp.94102s4117, 1994.

Atkinson, R. and Arey, J.: Mechanisms of the gas-phase reactions of aromatic hydrocarbons and PAHs with OH and NO3 radicals, Polycyclic Aromat. Compd., 27, 15-40, https://doi.org/10.1080/10406630601134243, 2007.

Atkinson, R., Aschmann, S. M., Arey, J., Zielinska, B., and Schuetzle, D.: Gas-phase atmospheric chemistry of 1Nitronaphthalene and 2-Nitronaphthalene and 1,4-Naphthoquinone, Atmos. Environ., 23, 2679-2690, https://doi.org/10.1016/0004-6981(89)90548-9, 1989.

Bamford, H. A. and Baker, J. E.: Nitro-polycyclic aromatic hydrocarbon concentrations and sources in urban and suburban atmospheres of the mid-Atlantic region, Atmos. Environ., 37, 2077-2091, https://doi.org/10.1016/S13522310(03)00102-X, 2003.

Bamford, H. A., Bezabeh, D. Z., Schantz, M. M., Wise, S. A., and Baker, J. E.: Determination and comparison of nitratedpolycyclic aromatic hydrocarbons measured in air and diesel particulate reference materials, Chemosphere, 50, 575587, https://doi.org/10.1016/S0045-6535(02)00667-7, 2003.

Bandowe, B. A. M., Meusel, H., Huang, R.-J., Ho, K., Cao, J., Hoffmann, T., and Wilcke, W.: PM 2.5 -bound oxygenated PAHs, nitro-PAHs and parent-PAHs from the atmosphere of a Chinese megacity: seasonal variation, sources and cancer risk assessment, Sci. Total Environ., 473-474, 77-87, http://dx.doi.org/10.1016/j.scitotenv.2013.11.108, 2014.

Bandowe, B. A. M. and Meusel, H.: Nitrated polycyclic aromatic hydrocarbons (nitro-PAHs) in the environment - A review, Sci. Total Environ., 581-582, 237-257, https://doi.org/10.1016/j.scitotenv.2016.12.115, 2017.

Baek, S. O., Field, R. A., Goldstone, M. E., Kirk, P. W., Lester, J. N., and Perry, R.: A review of atmospheric polycyclic aromatic hydrocarbons: Sources, fate and behaviour, Water Air Soil Pollut., 60, 279-300, https://doi.org/10.1007/BF00282628, 1991.

Bezabeh, D. Z., Bamford, H. A., Schantz, M. M., and Wise, S. A.: Determination of nitrated polycyclic aromatic hydrocarbons in diesel particulate-related standard reference materials by using gas chromatography/mass 
https://doi.org/10.5194/acp-2022-32

Preprint. Discussion started: 18 January 2022

(c) Author(s) 2022. CC BY 4.0 License.

Atmospheric

Chemistry

(c) (i)

and Physics

Discussions

spectrometry with negative ion chemical ionization, Anal. Bioanal. Chem., 375, 381-388, https://doi.org/10.1007/s00216-002-1698-8, 2003.

Bläsing, M., Kistler, M., and Lehndorff, E.: Emission fingerprint of inland navigation vessels compared with road traffic, domestic heating and ocean-going vessels, Org. Geochem., 99, 1-9, https://doi.org/10.1016/j.orggeochem.2016.05.009, 2016.

Brorström-Lundén, E., Remberger, M., Kaj, L., Hansson, K., Palm Cousins, A., Andersson, H., Haglund, P., Ghebremeskel, M., and Schlabach, M.: Results from the Swedish national screening programme 2008: Screening of unintentionally produced organic contaminants, report B1944, Swedish Environmental Research Institute (IVL), Gothenburg, Sweden, 2010.

Bolton, J. L., Trush, M. A., Penning, T.M., Dryhurst, G., and Monks, T. J.: Role of quinones in toxicology, Chem. Res. Toxicol., 13, 135-160, https://doi.org/10.1021/tx9902082, 2000.

Bourtsoukidis, E., Ernle, L., Crowley, J. N., Lelieveld, J., Paris, J.-D., Pozzer, A., Walter, D., and Williams, J.: Nonmethane hydrocarbon $(\mathrm{C} 2-\mathrm{C} 8)$ sources and sinks around the Arabian Peninsula, Atmos. Chem. Phys., 19, 7209-7232, https://doi.org/10.5194/acp-19-7209-2019, 2019.

Bourtsoukidis, E., Pozzer, A., Sattler, T., Matthaios, V. N., Ernle, L., Edtbauer, A., Fischer, H., Könemann, T., Osipov, S., Paris, J.-D., Pfannerstill, E. Y., Stönner, C., Tadic, I., Walter, D., Wang, N., Lelieveld, J., and Williams, J.: The Red Sea Deep Water is a potent source of atmospheric ethane and propane, Nat. Commun., 11, 447, https://doi.org/10.1038/s41467-020-14375-0, 2020.

Budzinski, H., Garrigues, P., Connan, J., Devillers, J., Domine, D., Radke, M., and Oudins, J. L.: Alkylated phenanthrene distributions as maturity and origin indicators in crude oils and rock extracts, Geochim. Cosmochim. Acta, 59, 20432056, https://doi.org/10.1016/0016-7037(95)00125-5, 1995.

Castro-Jiménez, J., Berrojalbiz, N., Wollgast, J., and Dachs, J.: Polycyclic aromatic hydrocarbons (PAHs) in the Mediterranean Sea: Atmospheric occurrence, deposition and decoupling with settling fluxes in the water column, Environ. Pollut., 166, 40-47, https://doi.org/10.1016/j.envpol.2012.03.003, 2012.

Caumo, S., Vicente, A., Custodio, D., Alves, C., and Vasconcellos, P.: Organic compounds in particulate and gaseous phase collected in the neighbourhood of an industrial complex in Sao Paulo (Brazil), Air Qual. Atmos. Hlth., 11, 271-283, https://doi.org/10.1007/s11869-017-0531-7, 2018.

Celik, S., Drewnick, F., Fachinger, F., Brooks, J., Darbyshire, E., Coe, H., Paris, J.-D., Eger, P. G., Schuladen, J., Tadic, I., Friedrich, N., Dienhart, D., Hottmann, B., Fischer, H., Crowley, J. N., Harder, H., and Borrmann, S.: Influence of vessel characteristics and atmospheric processes on the gas and particle phase of ship emission plumes: in situ measurements in the Mediterranean Sea and around the Arabian Peninsula, Atmos. Chem. Phys., 20, 4713-4734, https://doi.org/10.5194/acp-20-4713-2020, 2020.

Ciccioli, P., Cecinato, A., Brancaleoni, E., Frattoni, M., Zacchei, P., Miguel, A. H., and Vasconcellos, P. D.: Formation and transport of 2-nitrofluoranthene and 2-nitropyrene of photochemical origin in the troposphere, J. Geophys. Res.Atmos., 101, 19567-19581., https://doi.org/10.1029/95JD02118, 1996.

Charrier, J.G., and Anastasio, C.: On dithiothreitol (DTT) as a measure of oxidative potential for ambient particles: evidence for the importance of soluble transition metals, Atmos. Chem. Phys., 12, 11317-11350, https://doi.org/10.5194/acpd12-11317-2012, 2012.

Clergé, A., Le Goff, J., Lopez, C., Ledauphin, J., and Delépée, R.: Oxy-PAHs: occurrence in the environment and potential genotoxic/mutagenic risk assessment for human health, Crit. Rev. Toxicol., 49, 302-328, https://doi.org/10.1080/10408444.2019.1605333, 2019.

Collins, J. F., Brown, J. P., Alexeeff, G. V., and Salmon, A. G.: Potency equivalency factors for some polycyclic aromatic hydrocarbons and polycyclic aromatic hydrocarbon derivatives, Regul. Toxicol. Pharm., 28, 45-54, https://doi.org/10.1006/rtph.1998.1235, 1998.

915 Dang, J., Shi, X., Zhang, Q., Hu, J., Wang, W.: Mechanism and thermal rate constant for the gas-phase ozonolysis of acenaphthylene in the atmosphere, Sci. Tot. Environ., 514, 344-350, https://doi.org/10.1016/j.scitotenv.2014.12.009, 2015.

Degrendele, C., Okonski, K., Melymuk, L., Landlová, L., Kukuĉka, P., Ĉupr, P., and Klánová, J.: Size specific distribution of the atmospheric particulate PCDD/Fs, dl-PCBs and PAHs on a seasonal scale: Implications for cancer risks from inhalation, Atmos. Environ., 98, 410-416, https://doi.org/10.1016/j.atmosenv.2014.09.001, 2014. 
https://doi.org/10.5194/acp-2022-32

Preprint. Discussion started: 18 January 2022

(c) Author(s) 2022. CC BY 4.0 License.

Atmospheric

Chemistry

(c) $\underset{\mathrm{Br}}{\mathrm{B}}$

and Physics

Discussions

Di Filippo, P., Riccardi, C., Pomata, D., and Buiarelli, F.: Concentrations of PAHs, and nitro- and methyl-derivatives associated with a size segregated urban aerosol, Atmos. Environ., 44, 2742-2749, https://doi.org/10.1016/j.atmosenv.2010.04.035, 2010.

Drotikova, T., Ali, A. M., Halse, A. K., Reinardy, H. C., and Kallenborn, R.: Polycyclic aromatic hydrocarbons (PAHs), oxy-and nitro-PAHs in ambient air of Arctic town Longyearbyen, Svalbard, Atmos. Chem. Phys., 20, 9997-10014, https://doi.org/10.5194/acp-20-9997-2020, 2020.

Durant, J. L., Busby Jr., W. F., Lafleur, A. L., Penman, B. W., and Crespi, C. L.: Human cell mutagenicity of oxygenated, nitrated and unsubstituted polycyclic aromatic hydrocarbons associated with urban aerosols, Mutat. Res., 371, 123157, https://doi.org/10.1016/S0165-1218(96)90103-2, 1996.

ECHA - European Chemicals Agency: Grouping speeds up regulatory action - integrated regulatory strategy annual report 2020, https://doi.org/10.2823/092964, 2021.

Eger, P. G., Friedrich, N., Schuladen, J., Shenolikar, J., Fischer, H., Tadic, I., Harder, H., Martinez, M., Rohloff, R., Tauer, S., Drewnick, F., Fachinger, F., Brooks, J., Darbyshire, E., Sciare, J., Pikridas, M., Lelieveld, J., and Crowley, J. N.: Shipborne measurements of $\mathrm{ClNO}_{2}$ in the Mediterranean Sea and around the Arabian Peninsula during summer, Atmos. Chem. Phys., 19, 12121-12140, https://doi.org/10.5194/acp-19-12121-2019, 2019.

El Alawi, Y. S., McConkey, B. J., Dixon, D. G., and Greenberg, B. M.: Measurement of short and long-term toxicity of polycyclic aromatic hydrocarbons using luminescent bacteria, Ecotoxicol. Environ. Saf., 51, 12-21, https://doi.org/10.1006/eesa.2001.2108, 2002.

Fan, Z. H., Kamens, R. M., Hu, J. X., Zhang, J.B., and McDow, S.: Photostability of nitropolycyclic aromatic hydrocarbons on combustion soot particles in sunlight, Environ. Sci. Technol. 30, 1358-1364, https://doi.org/10.1016/13522310(94)00347-N, 1996.

Feilberg, A. and Nielsen, T.: Effect of aerosol chemical composition on the photodegradation of nitro-polycyclic aromatic hydrocarbons, Environ. Sci. Technol., 34, 789-97, https://doi.org/10.1021/es990566r, 2000.

Feilberg, A., Kamens, R. M., Strommen, M. R., and Nielsen, T.: Modeling the formation, decay, and partitioning of semivolatile nitro-polycyclic aromatic hydrocarbons (nitronaphthalenes) in the atmosphere, Atmos. Environ., 33, 1231-1243, https://doi.org/10.1016/S1352-2310(98)00275-1, 1999.

Feilberg, A., Poulsen, M. W. B., Nielsen, T., and Skov, H.: Occurrence and sources of particulate nitro-polycyclic aromatic hydrocarbons in ambient air in Denmark, Atmos. Environ., 35, 353-366, https://doi.org/10.1016/S1352$\underline{2310(00) 00142-4}, 2001$.

Finlayson-Pitts, B. J. and Pitts Jr, J. N.: Chemistry of the upper and lower atmosphere, $1^{\text {st }}$ edition, Academic Press, New York, United States, 1999.

Friedrich, N., Eger, P., Shenolikar, J., Sobanski, N., Schuladen, J., Dienhart, D., Hottmann, B., Tadic, I., Fischer, H., Martinez, M., Rohloff, R., Tauer, S., Harder, H., Pfannerstill, E. Y., Wang, N., Williams, J., Brooks, J., Drewnick, F., Su, H., Li, G., Cheng, Y., Lelieveld, J., and Crowley, J. N.: Reactive nitrogen around the Arabian Peninsula and in the Mediterranean Sea during the 2017 AQABA ship campaign, Atmos. Chem. Phys., 21, 7473-7498, https://doi.org/10.5194/acp-21-7473-2021, 2021.

Gao, S., Zhang, Y., Meng, J., and Shu, J.: Online investigations on ozonation products of pyrene and benz[a]anthracene particles with a vacuum ultraviolet photoionization aerosol time-of-flight mass spectrometer, Atmos. Environ., 43, 3319-25, https://doi.org/10.1016/j.atmosenv.2009.04.021, 2009.

Garcia, K. O., Teixeira, E. C., Agudelo-Castañeda, D. M., Braga, M., Alabarse, P. G., Wiegand, F., Kautzmann, R. M., and Silva, L. F. O.: Assessment of nitro-polycyclic aromatic hydrocarbons in $\mathrm{PM}_{1}$ near an area of heavy-duty traffic, Sci. Total Environ., 479-480, 57-65, https://doi.org/10.1016/j.scitotenv.2014.01.126, 2014.

Gogou, A., Stratigakis, N., Kanakidou, M. and Stephanou, E. G.: Organic aerosols in Eastern Mediterranean: components source reconciliation by using molecular markers and atmospheric back trajectories, Org. Geochem., 25, 79-96, https://doi.org/10.1016/S0146-6380(96)00105-2, 1996.

Harrison, R. M., Alam, M. S., Dang, J., Ismail, I. M., Basahi, J., Alghamdi, M. A., Hassan, I. A, and Khoder, M.: Relationship of polycyclic aromatic hydrocarbons with oxy(quinone) and nitro derivatives during air mass transport, Sci. Total Environ., 572, 1175-118, https://doi.org/10.1016/j.scitotenv.2016.08.030, 2016.

Heeb, N.V., Schmid, P., Kohler, M., Gujer, E., Zennegg, M., Wenger, D., Wichser, A., Ulrich, A., Gfeller, U., Honegger, P., Zeyer, K., Emmenegger, L., Petermann, J.L.,Czerwinski, J., Mosimann, T., Kasper, M., and Mayer, A.: Secondary 
https://doi.org/10.5194/acp-2022-32

Preprint. Discussion started: 18 January 2022

(c) Author(s) 2022. CC BY 4.0 License.

Atmospheric

Chemistry

(c) (i)

and Physics

Discussions

effects of catalytic diesel particulate filters: Conversion of PAHs versus formation of nitro-PAHs, Environ. Sci. Technol. 42, 3773-3779, https://doi.org/10.1021/es7026949, 2008.

Helmig, D. and Harger, W. P.: $\mathrm{OH}$ radical-initiated gas-phase reaction-products of phenanthrene, Sci. Total Environ., 148, 11-21, https://doi.org/10.1016/0048-9697(94)90368-9, 1994.

975

980

Hens, K., Novelli, A., Martinez, M., Auld, J., Axinte, R., Bohn, B., Fischer, H., Keronen, P., Kubistin, D., Nölscher, A. C., Oswald, R., Paasonen, P., Petäjä, T., Regelin, E., Sander, R., Sinha, V., Sipilä, M., Taraborrelli, D., Tatum Ernest, C., Williams, J., Lelieveld, J., and Harder, H.: Observation and modelling of $\mathrm{HO}_{\mathrm{x}}$ radicals in a boreal forest, Atmos. Chem. Phys., 14, 8723-8747, https://doi.org/10.5194/acp-14-8723-2014, 2014.

Iakovides, M., Apostolaki, M., and Stephanou, E. G.: PAHs, PCBs and organochlorine pesticides in the atmosphere of Eastern Mediterranean: Investigation of their occurrence, sources and gas-particle partitioning in relation to air mass transport pathways, Atmos. Environ., 244, 117931, https://doi.org/10.1016/j.atmosenv.2020.117931, 2021.

IARC (International Agency for Research on Cancer): Polynuclear aromatic compounds. Part 1. Chemical, environmental and experimental data. IARC monographs on the evaluation of carcinogenic risk of chemicals to humans, IARC, Vol. 32, Lyon, France, 1983.

IARC (International Agency for Research on Cancer): Diesel and gasoline exhausts and some nitroarenes, IARC monographs on the evaluation of carcinogenic risk of chemicals to humans, IARC, Vol. 105, Lyon, France, 1989.

IARC (International Agency for Research on Cancer): Agents classified by the IARC monographs, Vol. 1-123, http://monographs.iarc.fr/ENG/Classification/ClassificationsAlphaOrder.pdf, last access: 04 January 2022, 2018.

Jang, M. and McDow, S. R.: Products of benz[a]anthracene photodegradation in the presence of known organic constituents of atmospheric aerosols, Environ. Sci. Technol., 31, 1046-1053, https://doi.org/10.1021/es960559s, 1997.

Jariyasopit, N., Harner, T., Shin, C., and Park, R.: The effects of plume episodes on PAC profiles in the athabasca oil sands region, Environ. Pollut., 282, 1-9. https://doi.org/10.1016/j.envpol.2021.117014, 2021.

Jaward, F. M., Barber, J. L., Booij, K., and Jones, K. C.: Spatial distribution of atmospheric PAHs and PCNs along a northsouth Atlantic transect, Environ. Pollut., 132, 173-181, https://doi.org/10.1016/j.envpol.2004.03.029, 2004.

Johansson, L., Jalkanen, J.-P., and Kukkonen, J.: Global assessment of shipping emissions in 2015 on a high spatial and temporal resolution, Atmos. Environ., 167, 403-415, https://doi.org/10.1016/j.atmosenv.2017.08.042, 2017.

Kamens, R. M., Zhi-Hua, F., Yao, Y., Chen, D., Chen, S., and Vartianen, M.: A methodology for modeling the formation and decay of nitro-PAH in the atmosphere, Chemosphere, 28, 1623-1632, https://doi.org/10.1016/00456535(94)90421-9, 1994.

Kautzman, K. E., Surratt, J. D., Chan, M. N., Chan, A. W. H., S. P., Chhabra, P. S., Dalleska, N. F., Wennberg, P. O., Flagan, R. C., and Seinfeld, J.H.: Chemical composition of gas- and aerosol-phase products from the photooxidation of naphthalene, J. Phys. Chem. A, 114, 913, https://doi.org/10.1021/jp908530s, 2010.

Keith, L. H.: The source of U.S. EPA's sixteen PAH priority pollutants, Polycycl. Aromat. Compd., 35, 147-160, https://doi.org/10.1080/10406638.2014.892886, 2015.

Kelly, J. M., Ivatt, P. D., Evans, M. J., Kroll, J. H., Hrdina, A. I. H., Kohale, I. N., White, F.M., Engelward, B.P., and Selin, N.E.: Global cancer risk from unregulated polycyclic aromatic hydrocarbons. GeoHealth, 5, e2021GH000401, https://doi.org/10.1029/2021GH000401, 2021.

Keyte, I.J., Harrison, R.M., and Lammel, G.: Chemical reactivity and long-range transport potential of polycyclic aromatic hydrocarbons - a review, Chem. Soc. Rev., 42, 9333-9391, https://doi.org/10.1039/C3CS60147A, 2013.

1010 Kitanovski, Z., Shahpoury, P., Samara, C., Voliotis, A., and Lammel, G.: Composition and mass size distribution of nitrated and oxygenated aromatic compounds in ambient particulate matter from southern and central Europe - implications for the origin, Atmos. Chem. Phys., 20, 2471-2487, https://doi.org/10.5194/acp-20-2471-2020, 2020.

Lammel G.: Polycyclic aromatic compounds in the atmosphere - a review identifying research needs, Polycycl. Aromat. Compd., 35, 316-329, https://doi.org/10.1080/10406638.2014.931870, 2015.

1015 Lammel, G., Meixner, F. X., Vrana, B., Efstathiou, C. I., Kohoutek, J., Kukučka, P., Mulder, M. D., Přibylová, P., Prokeš, R., Rusina, T. P., Song, G.-Z., and Tsapakis, M.: Bidirectional air-sea exchange and accumulation of POPs (PAHs, PCBs, OCPs and PBDEs) in the nocturnal marine boundary layer, Atmos. Chem. Phys., 16, 6381-6393, https://doi.org/10.5194/acp-16-6381-2016, 2016.

Lammel, G., Mulder, M. D., Shahpoury, P., Kukučka, P., Lišková, H., Přibylová, P., Prokeš, R., and Wotawa, G.: Nitropolycyclic aromatic hydrocarbons - gas-particle partitioning, mass size distribution, and formation along transport in 
marine and continental background air, Atmos. Chem. Phys., 17, 6257-6270, https://doi.org/10.5194/acp-17-6257$\underline{2017}, 2017$.

Lammel, G., Kitanovski, Z., Kukuĉka, P., Novák, J., Arangio, A. M., Codling, G. P., Filippi, A., Hovorka, J., Kuta, J., Leoni, C., Přibylová, P., Prokeš, R., Sáňka, O., Shahpoury, P., Tong, H. J., and Wietzoreck, M.: Oxygenated and nitrated polycyclic aromatic hydrocarbons in ambient air levels, phase partitioning, mass size distributions, and inhalation bioaccessibility, Environ. Sci. Technol., 54, 2615-2625, https://doi.org/10.1021/acs.est.9b06820, 2020.

Lee, J. Y. and Lane, D. A.: Formation of oxidized products from the reaction of gaseous phenanthrene with the $\mathrm{OH}$ radical in a reaction chamber, Atmos. Environ., 44, 2469-2477, https://doi.org/10.1016/j.atmosenv.2010.03.008, 2010.

Lee, S., Hong, S., Liu, X., Kim, C., Jung, D., Yim, U. H., Shim, W. J., Khim, J. S., Giesy, J. P., and Choi, K.: Endocrine disrupting potential of PAHs and their alkylated analogues associated with oil spills, Environ. Sci.: Processes Impacts, 19, 1117, https://doi.org/10.1039/C7EM00125H, 2017.

Lee, W., Stevens, P. S., and Hites, R. A.: Rate constants for the gas-phase reactions of methylphenanthrenes with $\mathrm{OH}$ as a function of temperature, J. Phys. Chem. A, 107, 6603-6608, https://doi.org/10.1021/jp034159k, 2003.

Lelieveld, J., Berresheim, H., Borrmann, S., Crutzen, P. J., Dentener, F. J., Fischer, H., Feichter, J., Flatau, P. J., Heland, J., Holzinger, R., Korrmann, R., Lawrence, M. G., Levin, Z., Markowicz, K. M., Mihalopoulos, N., Minikin, A., Ramanathan, V., de Reus, M., Roelofs, G. J., Scheeren, H. A., Sciare, J., Schlager, H., Schultz, M., Siegmund, P., Steil, B., Stephanou, E. G., Stier, P., Traub, M., Warneke, C., Williams, J., and Ziereis, H.: Global air pollution crossroads over the Mediterranean, Science, 298, 794-799, https://doi.org/10.1126/science.1075457, 2002.

Lelieveld, J., Hoor, P., Jöckel, P., Pozzer, A., Hadjinicolaou, P., Cammas, J.-P., and Beirle, S.: Severe ozone air pollution in the Persian Gulf region, Atmos. Chem. Phys., 9, 1393-1406, https://doi.org/10.5194/acp-9-1393-2009, 2009.

Lelieveld, J., Evans, J. S., Fnais, M., Giannadaki, D., and Pozzer, A.: The contribution of outdoor air pollution sources to premature mortality on a global scale, Nature, 525, 367-371, https://doi.org/10.1038/nature15371, 2015.

Lelieveld, J., Klingmuller, K., Pozzer, A., Poschl, U., Fnais, M., Daiber, A., and Munzel, T.: Cardiovascular disease burden from ambient air pollution in Europe reassessed using novel hazard ratio functions, Eur. Heart J. 40, 1590-1596, $1045 \quad$ https://doi.org/10.1093/eurheartj/ehz135, 2019.

Li, W., Wang, C., Shen, H., Su, S., Shen, G., Huang, Y., Zhang, Y., Chen, Y., Chen, H., Lin, N., Zhuo, S., Zhong, Q., Wang, X., Liu, J., Li, B., Liu, W., and Tao, S.: Concentrations and origins of nitro-polycyclic aromatic hydrocarbons and oxy-polycyclic aromatic hydrocarbons in ambient air in urban and rural areas in northern China, Environ. Pollut. 197, 156-164, https://doi.org/10.1016/j.envpol.2014.12.019, 2015.

Lin, Y., Ma, Y., Qiu, X., Li, R., Fang, Y., Wang, J., Zhu, Y., and Hu, D.: Sources, transformation, and health implications of PAHs and their nitrated, hydroxylated, and oxygenated derivatives in $\mathrm{PM}_{2.5}$ in Beijing, J. Geophys. Res., 120, 72197228, http://dx.doi.org/10.1002/2015JD023628, 2015.

Liu, P., Ju, Y., Li, Y., Wang, Z., Mao, X., Cao, H., Jia, C., Huang, T., Gao, H., and Ma, J.: Spatiotemporal variation of atmospheric nitrated polycyclic aromatic hydrocarbons in semi-arid and petrochemical industrialized Lanzhou City, Northwest China, Environ. Sci. Pollut. Res., 26, 1857-1870, https://doi.org/10.1007/s11356-018-3633-3, 2019.

Lyu, Y., Guo, H., Cheng, T., and Li, X.: Particle size distributions of oxidative potential of lung-deposited particles: Assessing contributions from quinones and water-soluble metals, Environ. Sci. Technol., 52, 6592-6600, https://doi.org/10.1021/acs.est.7b06686, 2018.

Mandalakis, M., Tsapakis, M., Tsoga, A., and Stephanou, E. G.: Gas-particle concentrations and distribution of aliphatic hydrocarbons, PAHs, PCBs and PCDD/Fs in the atmosphere of Athens (Greece), Atmos. Environ., 36, 4023-4035, https://doi.org/10.1016/S1352-2310(02)00362-X, 2002.

Marino, F., Cecinato, A., and Siskos, P. A.: Nitro-PAH in ambient particulate matter in the atmosphere of Athens, Chemosphere, 40, 533-537, https://doi.org/10.1016/S0045-6535(99)00308-2, 2000.

Martinez, M., Harder, H., Kubistin, D., Rudolf, M., Bozem, H., Eerdekens, G., Fischer, H., Klüpfel, T., Gurk, C., Königstedt, R., Parchatka, U., Schiller, C. L., Stickler, A., Williams, J., and Lelieveld, J.: Hydroxyl radicals in the tropical troposphere over the Suriname rainforest: airborne measurements, Atmos. Chem. Phys., 10, 3759-3773, https://doi.org/10.5194/acp-10-3759-2010, 2010.

Meusel, H., Kuhn, U., Reiffs, A., Mallik, C., Harder, H., Martinez, M., Schuladen, J., Bohn, B., Parchatka, U., Crowley, J. N., Fischer, H., Tomsche, L., Novelli, A., Hoffmann, T., Janssen, R. H. H., Hartogensis, O., Pikridas, M., Vrekoussis, M., Bourtsoukidis, E., Weber, B., Lelieveld, J., Williams, J., Pöschl, U., Cheng, Y., and Su, H.: Daytime formation of 
https://doi.org/10.5194/acp-2022-32

Preprint. Discussion started: 18 January 2022

(c) Author(s) 2022. CC BY 4.0 License.

nitrous acid at a coastal remote site in Cyprus indicating a common ground source of atmospheric HONO and NO, Atmos. Chem. Phys., 16, 14475-14493, https://doi.org/10.5194/acp-16-14475-2016, 2016.

Minero, C., Maurino, V., Borghesi, D., Pelizzetti, E., and Vione, D.: An overview of possible processes able to account for the occurrence of nitro-PAHs in the Antarctic particulate matter, Microchem. J., 96, 213-216, https://doi.org/10.1016/j.microc.2009.07.013, 2010.

Nassar, H.F., Tang, N., Kameda, T., Toriba, A., Khoder, M. I., and Hayakawa, K.,: Atmospheric concentrations of polycyclic aromatic hydrocarbons and selected nitrated derivatives in Greater Cairo, Egypt, Atmos. Environ., 45, 7352-7359, https://doi.org/10.1016/j.atmosenv.2011.07.043, 2011.

1080 Nežiková, B., Degrendele, C., Bandowe, B. A. M., Smejkalova, A. H., Kukučka, P., Martiník, J., Mayer, L., Prokeš, R., Přibylova, P., Klánová, J., and Lammel, G.: Three years of atmospheric concentrations of nitrated and oxygenated polycyclic aromatic hydrocarbons and oxygen heterocycles at a central European background site, Chemosphere, 269, 128738, https://doi.org/10.1016/j.chemosphere.2020.128738, 2021.

Novelli, A., Hens, K., Tatum Ernest, C., Kubistin, D., Regelin, E., Elste, T., Plass-Dülmer, C., Martinez, M., Lelieveld, J., and Harder, H.: Characterisation of an inlet pre-injector laser-induced fluorescence instrument for the measurement of atmospheric hydroxyl radicals, Atmos. Meas. Tech., 7, 3413-3430, https://doi.org/10.5194/amt-7-3413-2014, 2014.

OEHHA (California Office of Environmental Health Hazard Assessment): Chemicals, https://oehha.ca.gov/chemicals/, last access: 02 December 2021.

Perraudin, E., Budzinski, H., and Villenave, E.: Identification and quantification of primary ozonation products of phenanthrene and anthracene adsorbed on silica particles, Atmos. Environ., 41, 6005-6017, https://doi.org/10.1016/j.atmosenv.2007.03.010, 2007.

Pfannerstill, E. Y., Wang, N., Edtbauer, A., Bourtsoukidis, E., Crowley, J. N., Dienhart, D., Eger, P. G., Ernle, L., Fischer, H., Hottmann, B., Paris, J.-D., Stönner, C., Tadic, I., Walter, D., Lelieveld, J., and Williams, J.: Shipborne measurements of total $\mathrm{OH}$ reactivity around the Arabian Peninsula and its role in ozone chemistry, Atmos. Chem. Phys., 19, 11501-11523, https://doi.org/10.5194/acp-19-11501-2019, 2019.

Polissar, A. V., Hopke, P. K., Paatero, P., Malm, W. C., and Sisler, J. F.: Atmospheric aerosol over Alaska: 2. Elemental composition and sources, J. Geophys. Res. 103, 19045-19057, https://doi.org/10.1029/98JD01212, 1998.

Ravindra, K., Sokhi, R., and Van Grieken, R.: Atmospheric polycyclic aromatic hydrocarbons: source attribution, emission factors and regulation, Atmos. Environ., 42, 2895-2921., https://doi.org/10.1016/j.atmosenv.2007.12.010, 2008.

Reisen, F. and Arey, J.: Atmospheric reactions influence seasonal PAH and nitro-PAH concentrations in the Los Angeles basin, Environ. Sci. Technol., 39, 64-73. https://doi.org/10.1021/es0354541, 2005.

Ringuet, J., Albinet, A., Leoz-Garziandia, E., Budzinski, H., and Villenave, E.: Reactivity of polycyclic aromatic compounds (PAHs, NPAHs and OPAHs) adsorbed on natural aerosol particles exposed to atmospheric oxidants, Atmos. Environ., 61, 15-22. http://dx.doi.org/10.1016/j.atmosenv.2012.07.025, 2012a.

Ringuet, J., Leoz-Garziandia, E., Budzinski, H., Villenave, E., and Albinet, A.: Particle size distribution of nitrated and oxygenated polycyclic aromatic hydrocarbons (NPAHs and OPAHs) on traffic and suburban sites of a European megacity: Paris (France), Atmos. Chem. Phys., 12, 8877-8887, https://doi.org/10.5194/acp-12-8877-2012, 2012b.

Rosu, A., Rosu, B., Constantin, D. E., Arseni, M., Voiculescu, M., Georgescu, L. P., and Popa, I. Overview of tropospheric $\mathrm{NO}_{2}$ using the ozone monitoring observations instrument and human perception about air quality for the most polluting countries accross the world, Carpathian J. Earth Environ. Sci., 14, 423-430, https://doi.org/10.26471/cjees/2019/014/091, 2019.

Schaub, D., Brunner, D., Boersma, K. F., Keller, J., Folini, D., Buchmann, B., Berresheim, H., and Staehelin, J.: SCIAMACHY tropospheric $\mathrm{NO}_{2}$ over Switzerland: estimates of $\mathrm{NO}_{\mathrm{x}}$ lifetimes and impact of the complex Alpine topography on the retrieval, Atmos. Chem. Phys., 7, 5971-5987, https://doi.org/10.5194/acp-7-5971-2007, 2007.

Scipioni, C., Villanueva, F., Pozo, K., and Mabilia, R.: Preliminary characterization of polycyclic aromatic hydrocarbons, nitrated polycyclic aromatic hydrocarbons and polychlorinated dibenzo-p-dioxins and furans in atmospheric $\mathrm{PM}_{10}$ of an urban and a remote area of Chile, Environ. Technol., 33, 809-820, https://doi.org/10.1080/09593330.2011.597433, 2012.

Seibert, P. and Frank, A.: Source-receptor matrix calculation with a Lagrangian particle dispersion model in backward mode, Atmos. Chem. Phys., 4, 51-63, https://doi.org/10.5194/acp-4-51-2004, 2004. 
Shah, V., Jacob, D. J., Li, K., Silvern, R. F., Zhai, S., Liu, M., Lin, J., and Zhang, Q.: Effect of changing $\mathrm{NO}_{x}$ lifetime on the seasonality and long-term trends of satellite-observed tropospheric $\mathrm{NO}_{2}$ columns over China, Atmos. Chem. Phys., 20, 1483-1495, https://doi.org/10.5194/acp-20-1483-2020, 2020.

Shen, J., Zhang, S., Lian, J., Kong, L., and Chen, J.: Benz[a]anthracene heterogeneous photochemical reaction on the surface of $\mathrm{TiO}_{2}$ particles, Acta Phys. Chim. Sin., 23, 1531-1536, https://doi.org/10.1016/S1872-1508(07)60078-3, 2007.

Shiraiwa, M., Garland, R. M., and Pöschl, U.: Kinetic double-layer model of aerosol surface chemistry and gas-particle interactions (K2-SURF): Degradation of polycyclic aromatic hydrocarbons exposed to $\mathrm{O}_{3}, \mathrm{NO}_{2}, \mathrm{H}_{2} \mathrm{O}, \mathrm{OH}$ and $\mathrm{NO}_{3}$, Atmos. Chem. Phys., 9, 9571-9586, https://doi.org/10.5194/acp-9-9571-2009, 2009.

Shiraiwa, M., Ueda, K., Pozzer, A., Lammel, G., Kampf, C. J., Fushimi, A., Enami, S., Arangio, A. M., Fröhlich-Nowoisky, J., Fujitani, Y., Furuyama, A., Lakey, P. S. J., Lelieveld, J., Lucas, K., Morino, Y., Pöschl, U., Takahama, S., Takami, A., Tong, H., Weber, B., Yoshino, A., and Sato, K.: Aerosol health effects from molecular to global scales, Environ. Sci. Technol., 51, 1354513567, https://doi.org/10.1021/acs.est.7b04417, 2017.

Stohl, A., Forster, C., Frank, A., Seibert, P., and Wotawa, G.: Technical note: The Lagrangian particle dispersion model FLEXPART version 6.2, Atmos. Chem. Phys., 5, 2461-2474, https://doi.org/10.5194/acp-5-2461-2005, 2005.

Streibel, T., Schnelle-Kreis, J., Czech, H., Harndorf, H., Jakobi, G., Jokiniemi, J., Karg, E., Lintelmann, J., Matuschek, G., Michalke, B., Müller, L., Orasche, J., Passig, J.,Radischat, C., Rabe, R., Reda, A., Rüger, C., Schwemer, T., Sippula, O., Stengel, B.,Sklorz, M., Torvela, T., Weggler, B., and Zimmermann, R.: Aerosol emissions of a ship diesel engine operated with diesel fuel or heavy fuel oil, Environ. Sci. Pollut. Res., 24, 10976-10991, https://doi.org/10.1007/s11356-016-6724-z, 2017.

Sverdrup, L. E., Ekelund, F., Krogh, P. H., Nielsen, T., and Johnsen, K.: Soil microbial toxicity of eight polycyclic aromatic compounds: effects on nitrification, the genetic diversity of bacteria, and the total number of protozoans, Environ. Toxicol. Chem., 21, 1644-1650, https://doi.org/10.1002/etc.5620210815, 2002a.

Sverdrup, L. E., Krogh, P. H., Nielsen, T., and Stenersen, J.: Relative sensitivity of three terrestrial invertebrate tests to polycyclic aromatic compounds, Environ. Toxicol. Chem., 21, 1927-1933, https://doi.org/10.1002/etc.5620210921, $2002 \mathrm{~b}$.

1145 Tadic, I., Crowley, J. N., Dienhart, D., Eger, P., Harder, H., Hottmann, B., Martinez, M., Parchatka, U., Paris, J.-D., Pozzer, A., Rohloff, R., Schuladen, J., Shenolikar, J., Tauer, S., Lelieveld, J., and Fischer, H.: Net ozone production and its relationship to nitrogen oxides and volatile organic compounds in the marine boundary layer around the Arabian Peninsula, Atmos. Chem. Phys., 20, 6769-6787, https://doi.org/10.5194/acp-20-6769-2020, 2020.

Tang, N., Sato, K., Tokuda, T., Tatematsu, M., Hama, H., Suematsu, C., Kameda, T., Toriba, A., and Hayakawa, K.: Factors affecting atmospheric 1-, 2-nitropyrenes and 2-nitrofluoranthene in winter at Noto Peninsula, a remote background site, Japan, Chemosphere, 107, 324-330, https://doi.org/10.1016/j.chemosphere.2013.12.077, 2014.

Tobiszewski, M. and Namieśnik, J.: PAH diagnostic ratios for the identification of pollution emission sources, Environ. Pollut., 162, 110-119, https://doi.org/10.1016/j.envpol.2011.10.025, 2012.

Tomaz, S., Shahpoury, P., Jaffrezo, J. L., Lammel, G., Perraudin, E., Villenave, E., and Albinet, A.: One-year study of polycyclic aromatic compounds at an urban site in Grenoble (France): seasonal variations, gas/particle partitioning and cancer risk estimation, Sci. Total Environ., 565, 1071-1083, http://dx.doi.org/10.1016/j.scitotenv.2016.05.137, 2016.

Tomaz, S., Jaffrezo, J.-L., Favez, O., Perraudin, E., Villenave, E., and Albinet, A.: Sources and atmospheric chemistry of oxy- and nitro-PAHs in the ambient air of Grenoble (France), Atmos. Environ., 161, 144-154, https://doi.org/10.1016/j.atmosenv.2017.04.042, 2017.

Tsapakis, M. and Stephanou, E. G.: Occurrence of gaseous and particulate polycyclic aromatic hydrocarbons in the urban atmosphere: study of sources and ambient temperature effect on the gas/particle concentration and distribution, Environ. Pollut., 133, 147-156, https://doi.org/10.1016/j.envpol.2004.05.012, 2005.

Tsapakis, M. and Stephanou, E. G.: Diurnal cycle of PAHs, nitro-PAHs, and oxy-PAHs in a high oxidation capacity marine background atmosphere, Environ. Sci. Technol., 41, 8011-8017, https://doi.org/10.1021/es071160e, 2007.

Turcotte, D., Akhtar, P., Bowerman, M., Kiparissis, Y., Brown, R. S., and Hodson, P. V.: Measuring the toxicity of alkylphenanthrenes to early life stages of medaka (Oryzias latipes) using partition controlled delivery, Environ. Toxicol. Chem., 30, 487-495, https://doi.org/10.1002/etc.404, 2011. 
USEPA (United States Environmental Protection Agency): Estimation Programs Interface Suite ${ }^{\mathrm{TM}}$ for Microsoft ${ }^{\circledR}$ Windows, $\mathrm{v} 4.11,2019$.

Valavanidis, A., Vlachogianni, T., Triantafyllaki, S., Dassenakis, M., Androutsos, F., and Scoullos, M.: Polycyclic aromatic hydrocarbons in surface seawater and in indigenous mussels (Mytilus galloprovincialis) from coastal areas of the Saronikos Gulf (Greece), Estuar. Coast. Shelf Sci., 79, 733-739, https://doi.org/10.1016/j.ecss.2008.06.018, 2008.

Verma, V., Wang, Y., El-Afifi, R., Fang, T., Rowland, J., Russell, A. G., and Weber, R. J.: Fractionating ambient humic-like substances (HULIS) for their reactive oxygen species activity - Assessing the importance of quinones and atmospheric aging, Atmos. Environ., 120, 351-359, https://doi.org/10.1016/j.atmosenv.2015.09.010, 2015.

Vincenti, M., Maurino, V., Minero, C., and Pelizzetti, E.: Detection of nitro-substituted polycyclic aromatic hydrocarbons in the Antarctic airborne particulate, Int. J. Environ. Anal. Chem., 79, 257-272, https://doi.org/10.1080/03067310108044388, 2001.

1180 Walgraeve, C., Demeestere, K., Dewulf, J., Zimmermann, R., and Van Langenhove, H.: Oxygenated polycyclic aromatic hydrocarbons in atmospheric particulate matter: molecular characterization and occurrence, Atmos. Environ., 44, 1831-1846, https://doi.org/10.1016/j.atmosenv.2009.12.004, 2010.

Wang, L., Atkinson, R., and Arey, J.: Formation of 9,10-phenanthrenequinone by atmospheric gas-phase reactions of phenanthrene, Atmos. Environ., 41, 2025-35, https://doi.org/10.1016/j.atmosenv.2006.11.008, 2007.

Wang, N., Edtbauer, A., Stönner, C., Pozzer, A., Bourtsoukidis, E., Ernle, L., Dienhart, D., Hottmann, B., Fischer, H., Schuladen, J., Crowley, J. N., Paris, J.-D., Lelieveld, J., and Williams, J.: Measurements of carbonyl compounds around the Arabian Peninsula: overview and model comparison, Atmos. Chem. Phys., 20, 10807-10829, https://doi.org/10.5194/acp-20-108072020, 2020.

Wassenaar, P. N. H. and Verbruggen, E. M. J.: Persistence, bioaccumulation and toxicity-assessment of petroleum UVCBs: A case study on alkylated three-ring PAHs, Chemosphere 276, 130113, https://doi.org/10.1016/j.chemosphere.2021.130113, 2021.

Wei, C., Han, Y. M., Bandowe, B. A. M., Cao, J. J., Huang, R. J., Ni, H. Y., Tian, J., and Wilcke, W.: Occurrence, gas/particle partitioning and carcinogenic risk of polycyclic aromatic hydrocarbons and their oxygen and nitrogen containing derivatives in Xi'an, central China, Sci. Total Environ., 505, 814-822,

\section{$1195 \quad$ http://dx.doi.org/10.1016/j.scitotenv.2014.10.054, 2015.}

Wilson, J., Octaviani, M., Bandowe, B. A. M., Wietzoreck, M., Zetzsch, C., and Pöschl, U.: Modeling the formation, degradation, and spatiotemporal distribution of 2-nitrofluoranthene in the global atmosphere, Environ. Sci. Technol., 54, 14224-14234, https://doi.org/10.1021/acs.est.0c04319, 2020.

Xiong, Q., Yu, H., Wang, R., Wei, J., and Verma, V.: Rethinking dithiothreitol-based particulate matter oxidative potential: measuring dithiothreitol consumption versus reactive oxygen species generation, Environ. Sci. Technol., 51, 65076514, https://doi.org/10.1021/acs.est.7b01272, 2017.

Zhang, J., Yang, L., Mellouki, A., Chen, J., Chen, X., Gao, Y., Jiang, P., Li, Y., Yu, H., and Wang, W: Atmospheric PAHs, NPAHs, and OPAHs at an urban, mountainous, and marine sites in Northern China: Molecular composition, sources, and ageing, Atmos. Environ., 173, 256-264, https://doi.org/10.1016/j.atmosenv.2017.11.002, 2018.

Zhao, J., Zhang, Y., Wang, T., Sun, L., Yang, Z., Lin, Y., Chen, Y., and Mao, H.: Characterization of PM 2.5 -bound polycyclic aromatic hydrocarbons and their derivatives (nitro-and oxy-PAHs) emissions from two ship engines under different operating conditions, Chemosphere, 225, 43-52, https://doi.org/10.1016/j.chemosphere.2019.03.022, 2019.

Zhao, J., Zhang, Y., Chang, J., Peng, S., Hong, N., Hu, J., Ly, J., Wang, T., and Mao, H.: Emission characteristics and temporal variation of PAHs and their derivatives from an ocean-going cargo vessel, Chemosphere, 249, 126194, https://doi.org/10.1016/j.chemosphere.2020.126194, 2020.

Zhao, Y., Cao, L., Zhou, Q., Que, Q., and Hong, B.: Effects of oil pipeline explosion on ambient particulate matter and their associated polycyclic aromatic hydrocarbons, Environ. Pollut., 196, 440-449, https://doi.org/10.1016/j.envpol.2014.11.012, 2015.

Zhuo, S., Du, W., Shen, G., Li, B., Liu, J., Cheng, H., Xing, B., and Tao, S.: Estimating relative contributions of primary and secondary sources of ambient nitrated and oxygenated polycyclic aromatic hydrocarbons, Atmos. Environ., 159, 126134, http://dx.doi.org/10.1016/j.atmosenv.2017.04.003, 2017. 
https://doi.org/10.5194/acp-2022-32

Preprint. Discussion started: 18 January 2022

(C) Author(s) 2022. CC BY 4.0 License.

(c) (1)

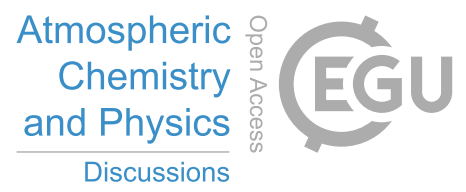

Zimmermann, K., Atkinson, R., Arey, J., Kojima, Y., and Inazu, K.: Isomer distributions of molecular weight 247 and 273 nitro-PAHs in ambient samples, NIST Diesel SRM, and from radical-initiated chamber reactions, Atmos. Environ, 55, 431-439, https://doi.org/10.1016/j.atmosenv.2012.03.016, 2012. 